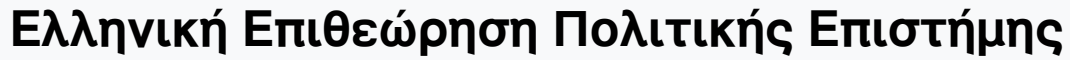

Tón. 21, Ap. 1 (2003)

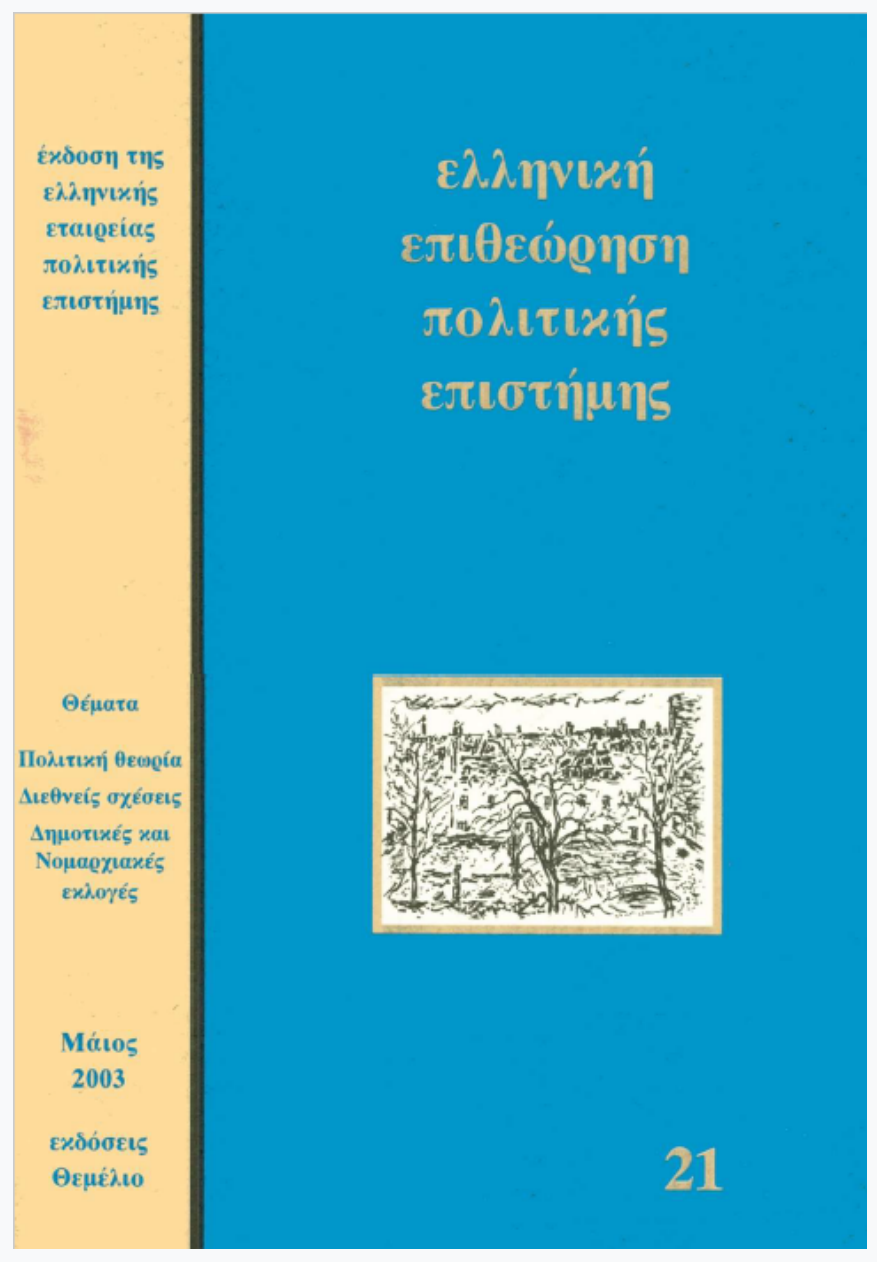

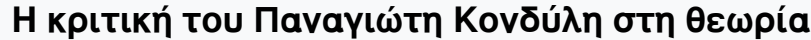

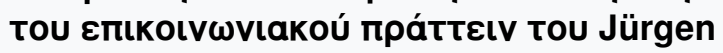 Habermas}

\section{Nıкódaos Toípos}

doi: $10.12681 / \mathrm{hpsa} .14756$

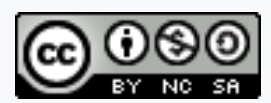

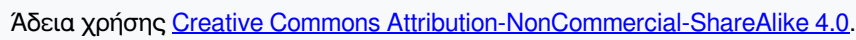

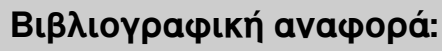

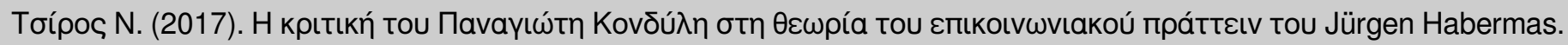

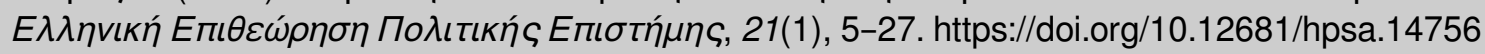




\section{H KPITIKH TOY ПANAГI $\Omega T H ~ K O N \triangle Y \Lambda H$ $\Sigma$ TH $\Theta E \Omega P I A$ TOY EMIKOINSNIAKOY ПPATTEIN TOY JURGEN HABERMAS}

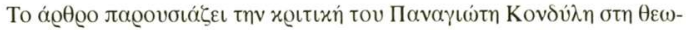

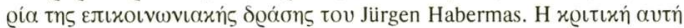

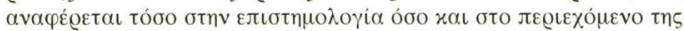

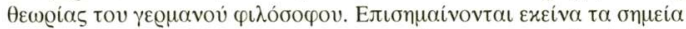

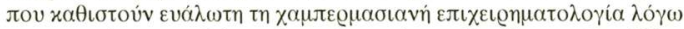

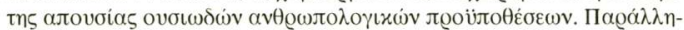

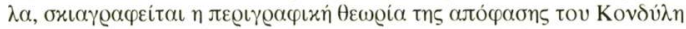

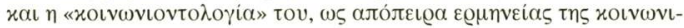

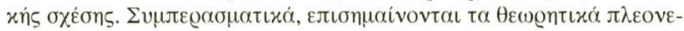

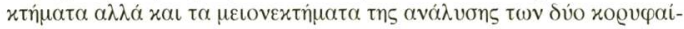

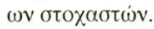

\section{1. $\mathrm{EI \Sigma AГ \Omega \Gamma H}$}

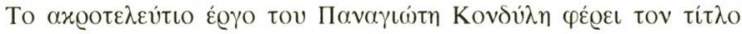

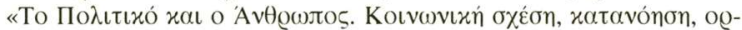

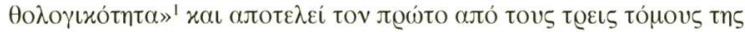

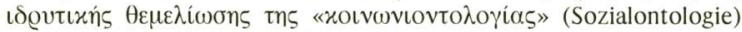

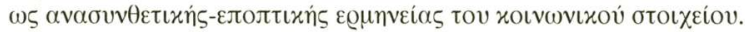

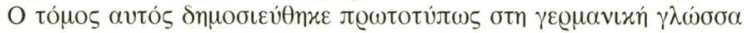

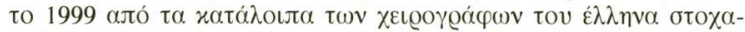

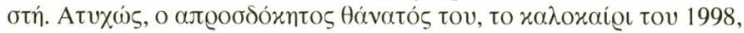

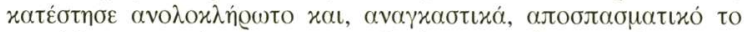

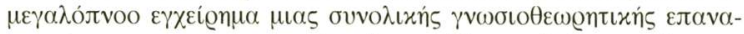

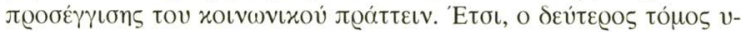

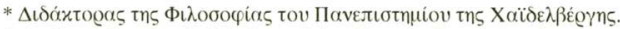

1. P. Kondylis, Das Politische und der Mensch: Grundzige der Sozialontologie, Band I, Soziale Beziehung, Verstehen, Rationalität, Akademie Verlag, Beøoגívo 1999. 


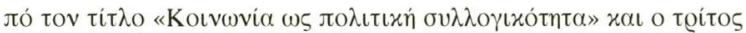

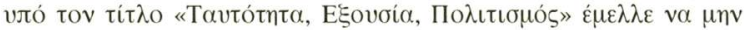

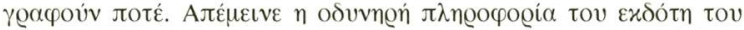

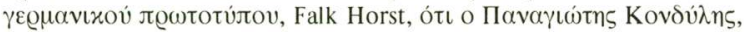

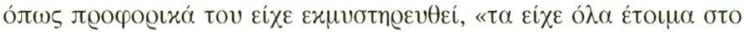

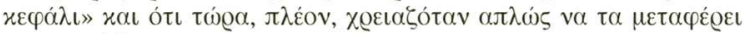
бто $\chi \alpha \varrho \tau i .^{2}$

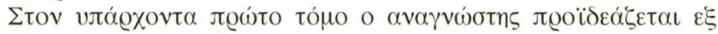

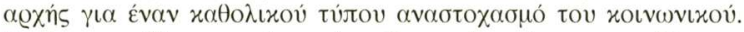

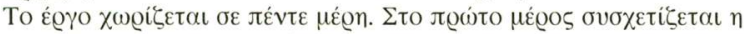

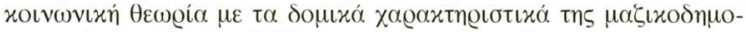

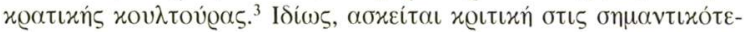

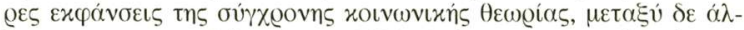

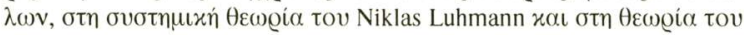

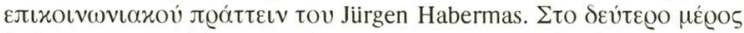

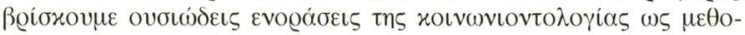

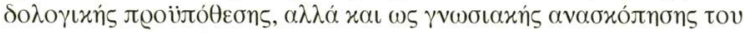

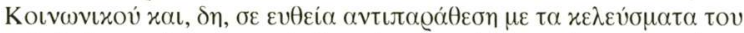

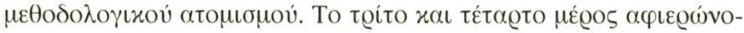

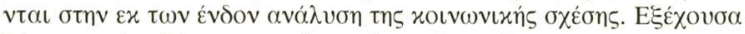

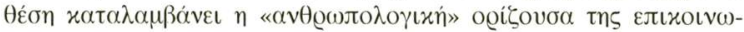

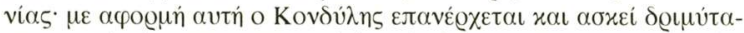

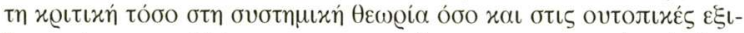

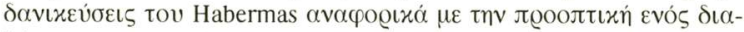

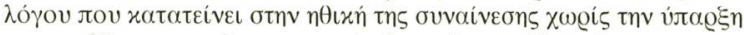
олоเ

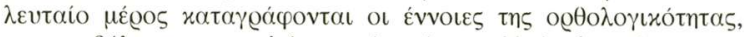

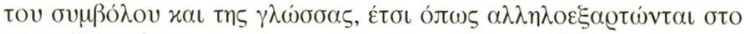

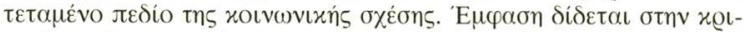

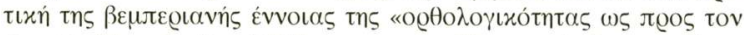

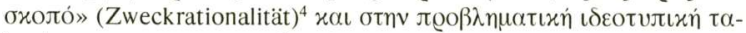

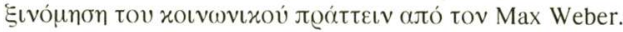

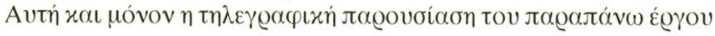

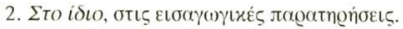

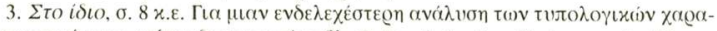

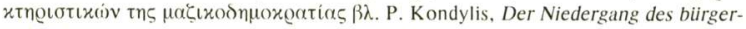
lichen Denk - und Lebensform. Die liberale Moderne und die massendemokratische Postmoderne, Act Humaniora. Weinheim 1991. б. 188-208.

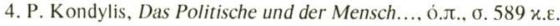




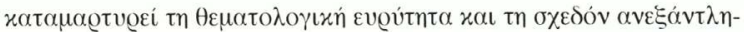

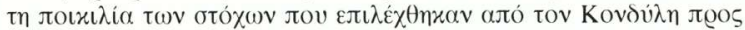

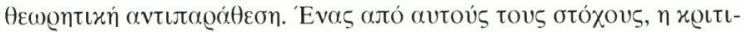

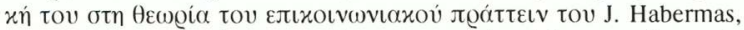

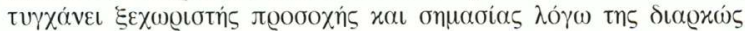

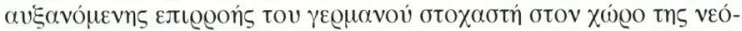

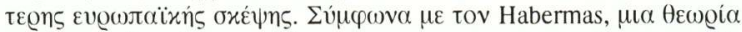

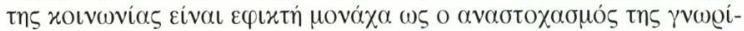

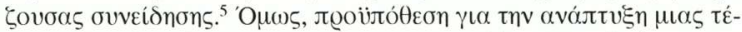

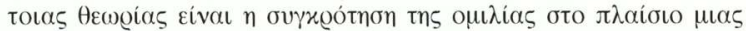

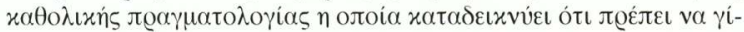

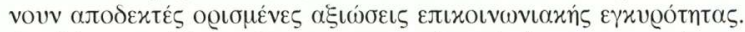

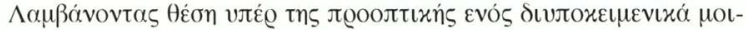

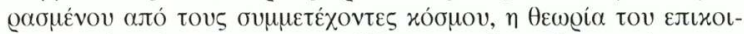

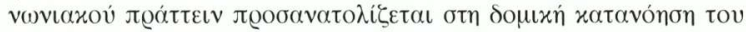

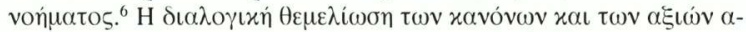

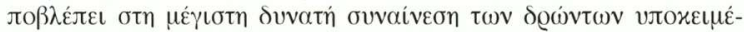

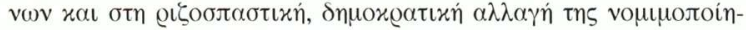

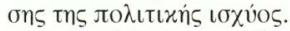

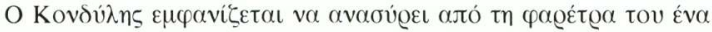

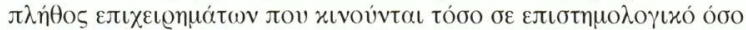

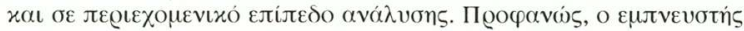

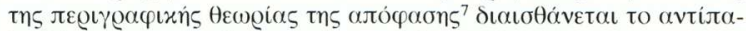

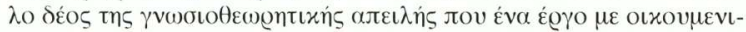

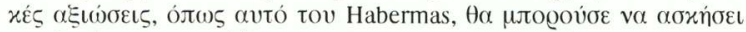

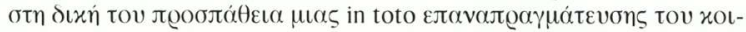

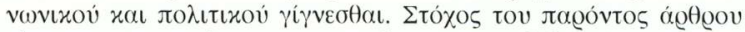

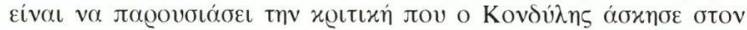

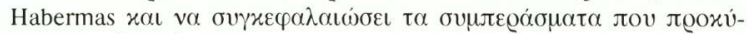

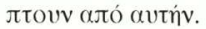

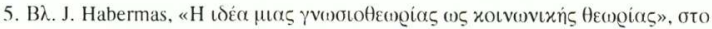

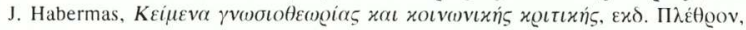
Atท́vo 1990, б. 64.

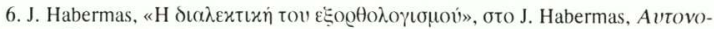

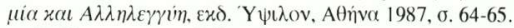

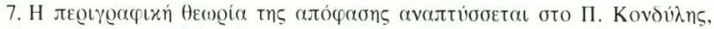

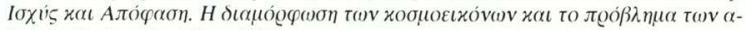

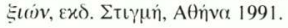




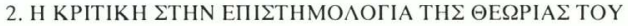
EПIKOINSNIAKOY ПPATTEIN

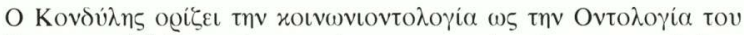

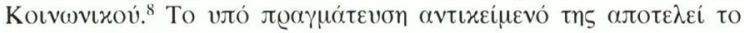

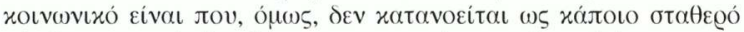

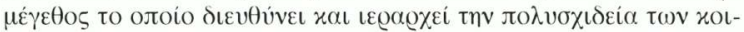

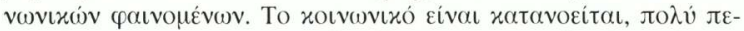

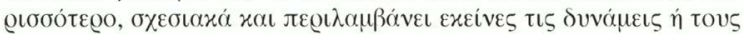

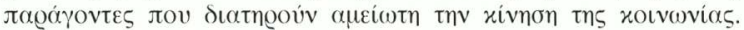

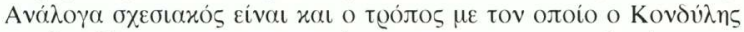

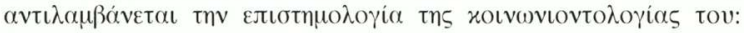

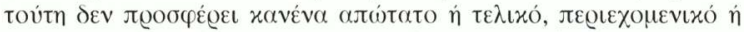

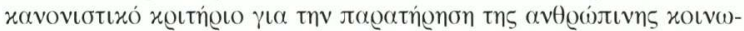

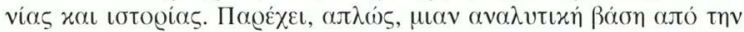

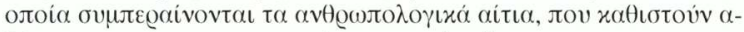

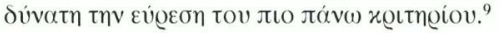

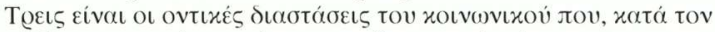

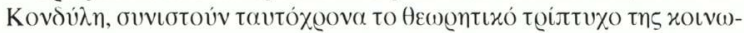

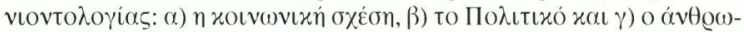

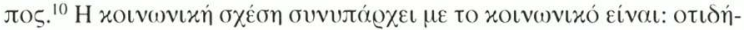

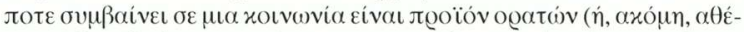

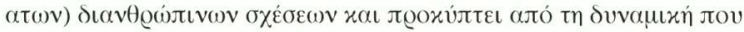

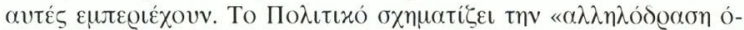

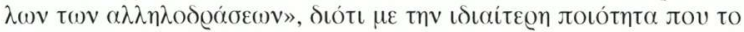

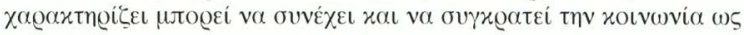

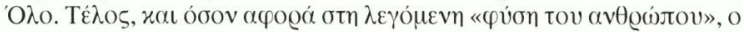

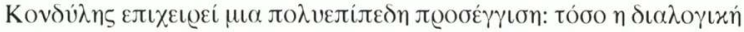

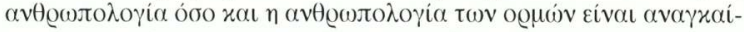

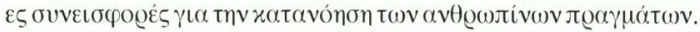

X

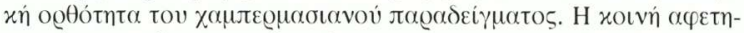

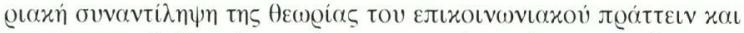

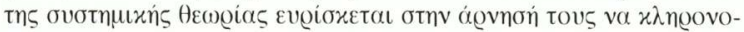

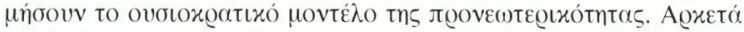

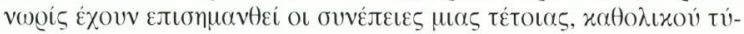

8. P. Kondylis, Das Politische und der Mensch..., o. đ., б. 196.

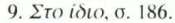

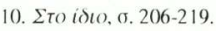




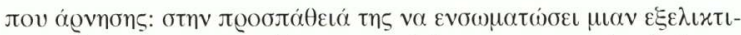

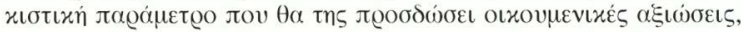

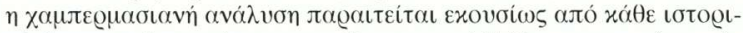

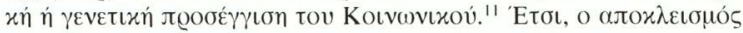

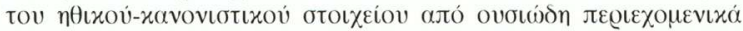
$\mu \varepsilon \gamma \varepsilon \dot{\theta}$ оп

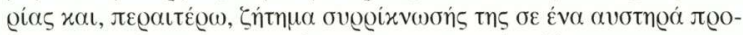

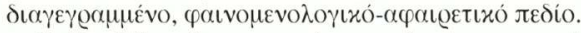

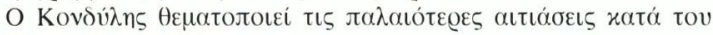

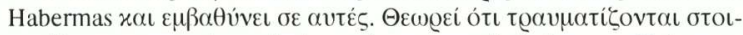

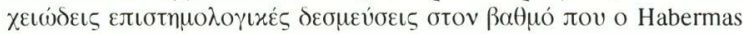

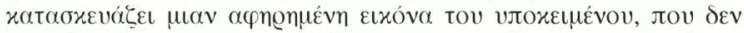

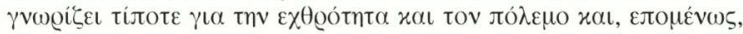

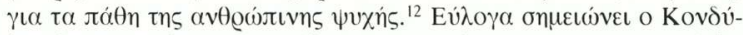

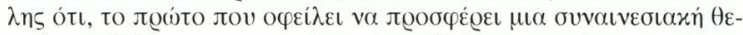

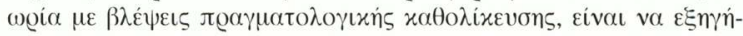

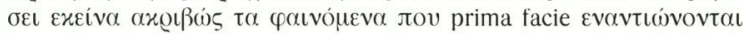

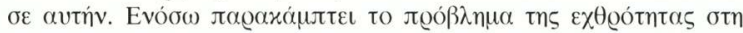

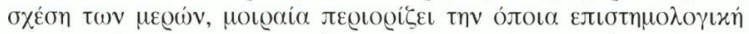

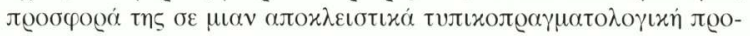

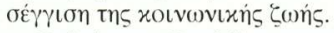

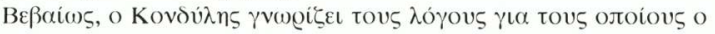

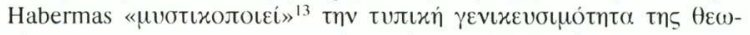

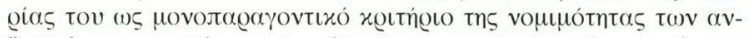

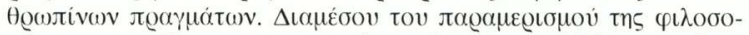

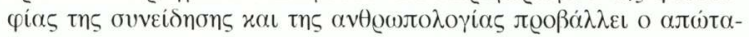

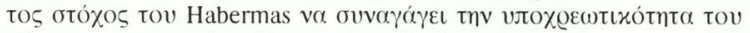

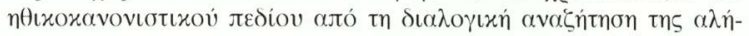

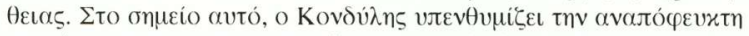

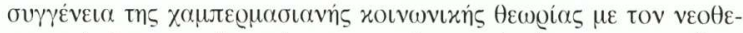

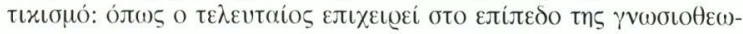

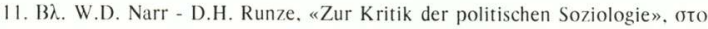

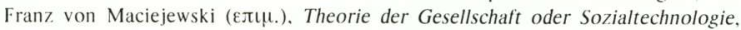

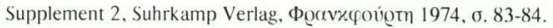

12. P. Kondylis, Das Politische und der Mensch..., ó.л., б. 27.

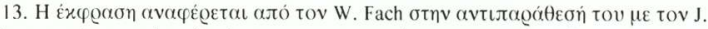

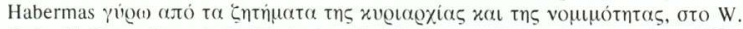

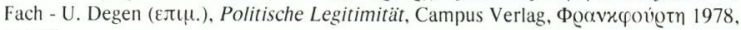
б. 119. 


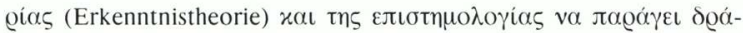

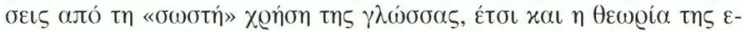

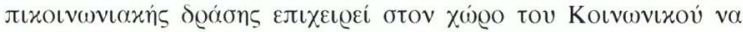

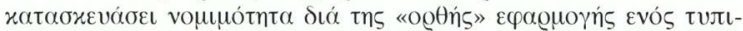

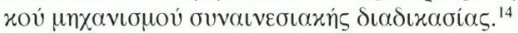

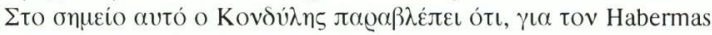

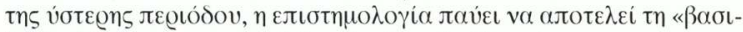

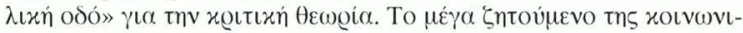
xท́

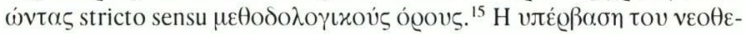

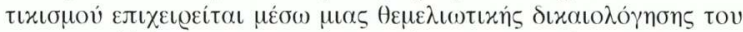

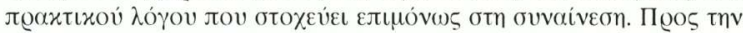

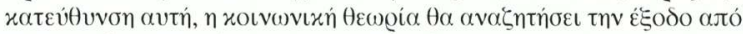

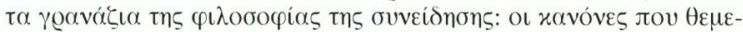

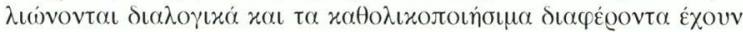

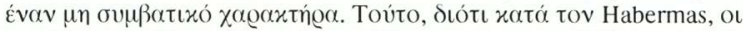

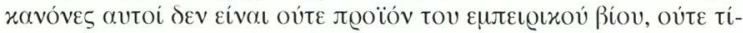

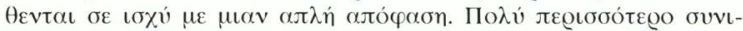

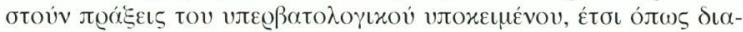

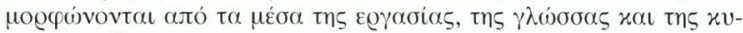
etaoxias. ${ }^{16}$

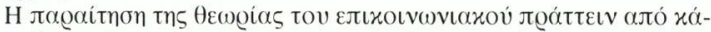

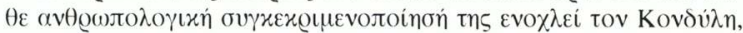

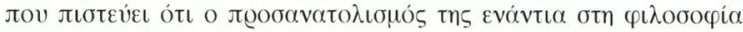

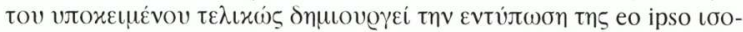

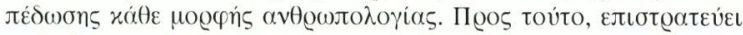

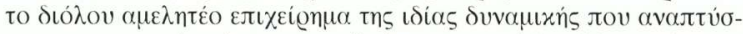

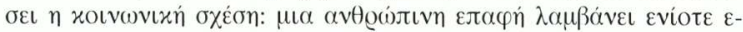

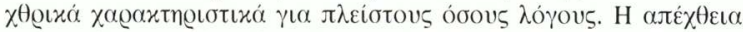

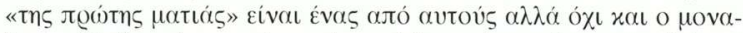

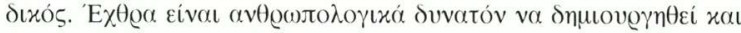

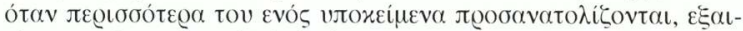

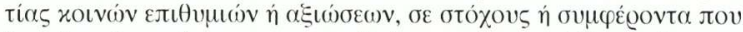

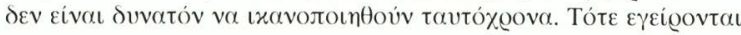

14. P. Kondylis, ó.л., о. 28.

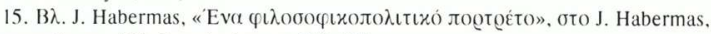

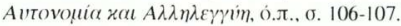

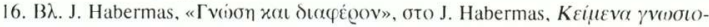

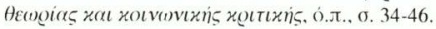




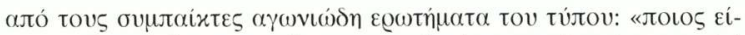

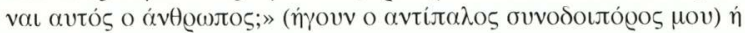

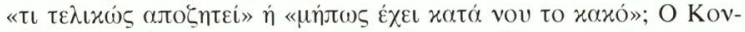

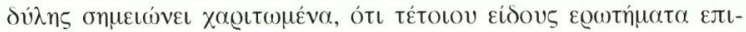

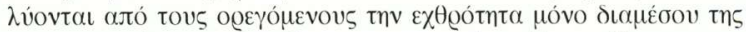

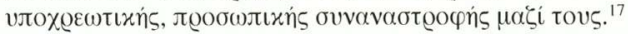

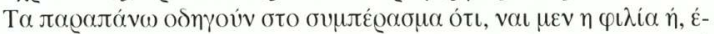

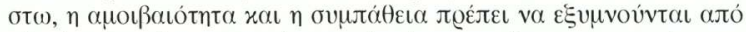

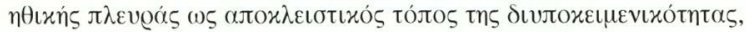

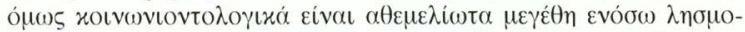

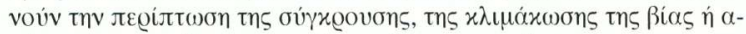
xó

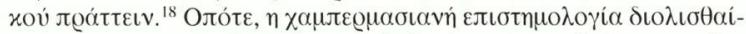

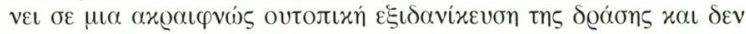

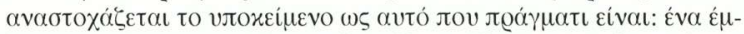

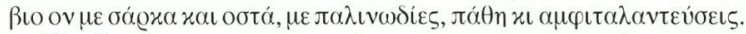

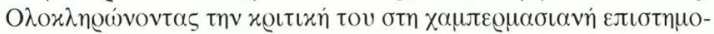

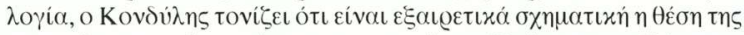

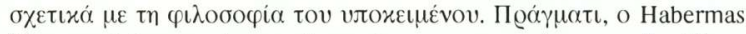

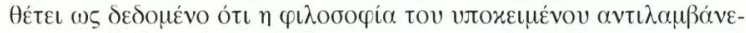

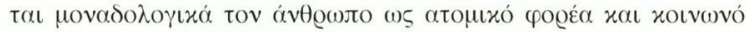

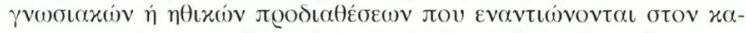

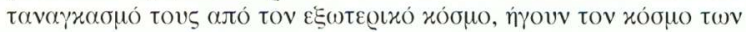

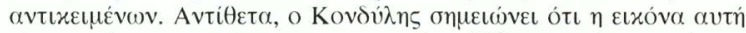

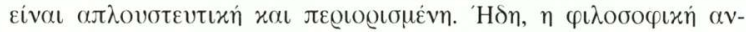

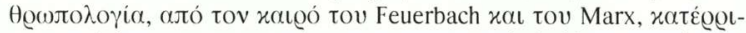

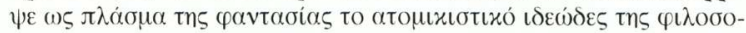

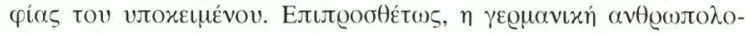

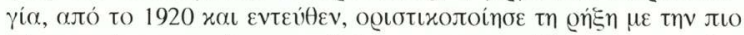

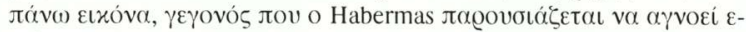

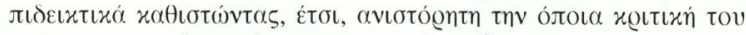

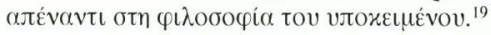

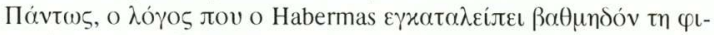

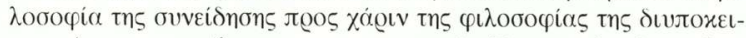

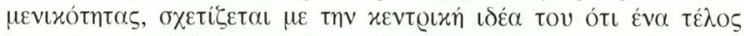

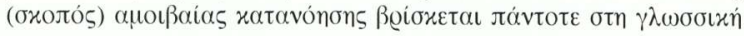

17. P. Kondylis, о́.л., б. 403.

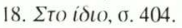

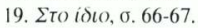




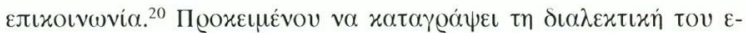

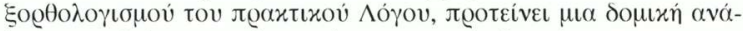

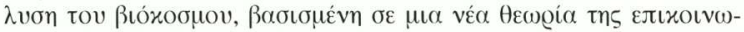

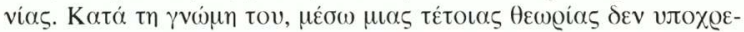

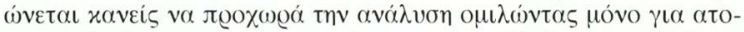

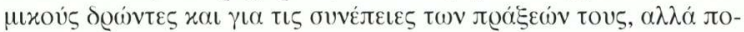

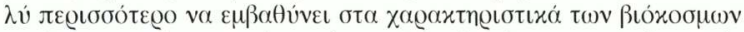

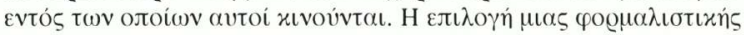

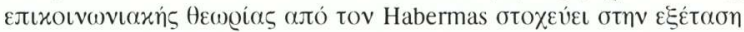

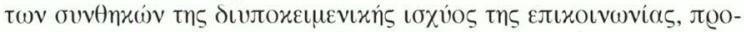

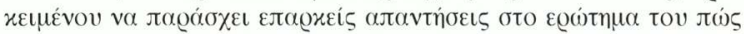

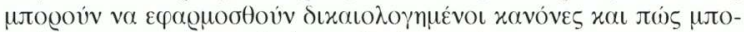

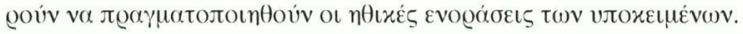

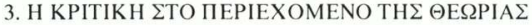 TOY EПIKOINSNIAKOY ПPATTEIN}

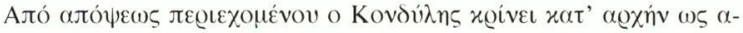

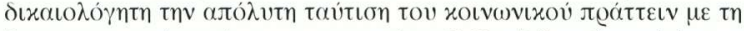

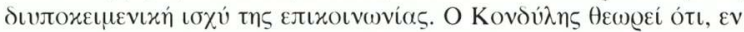

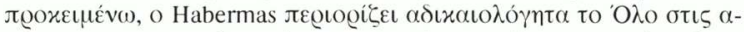

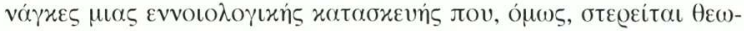

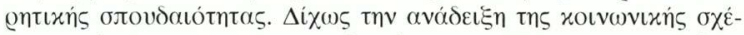

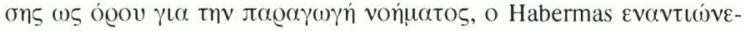

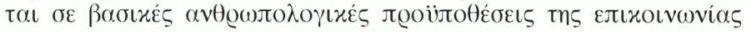

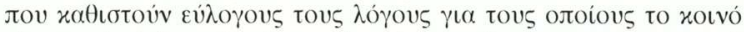

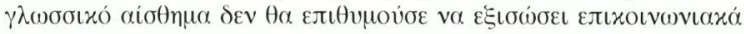

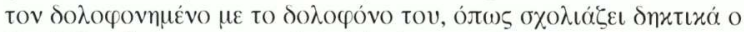

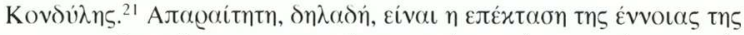

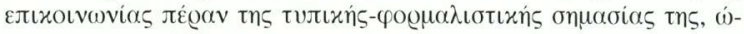

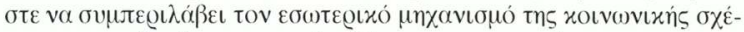

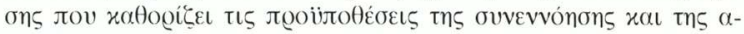

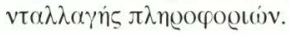

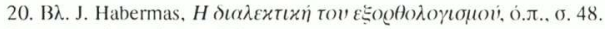

21. P. Kondylis, O.л., б. 392. 


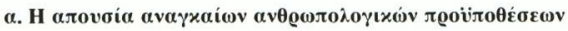

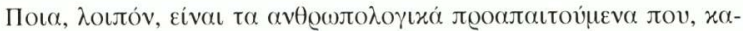

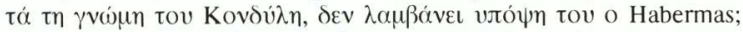

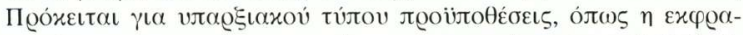

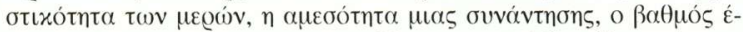

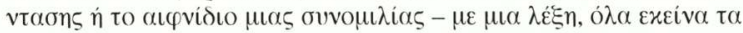

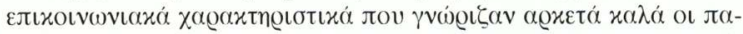

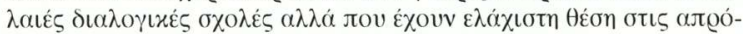

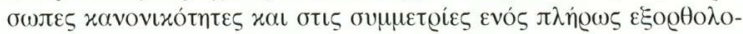

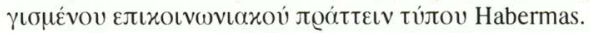

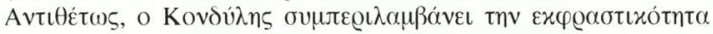

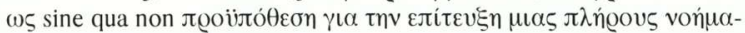

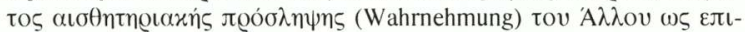

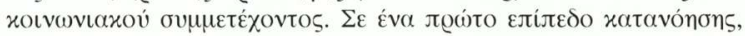

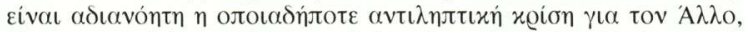

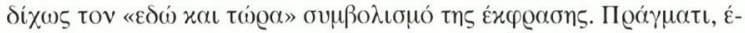

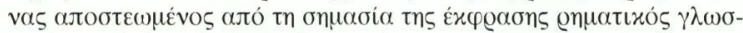

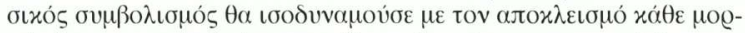

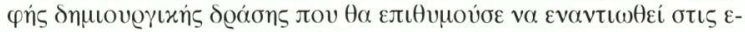

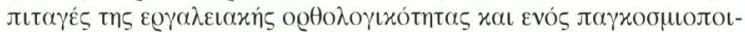

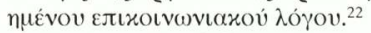

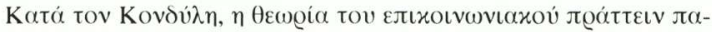

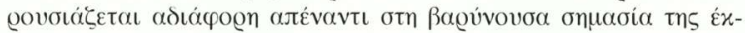

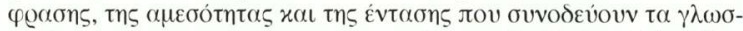

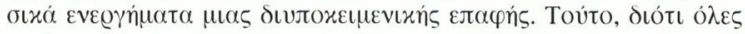
ol

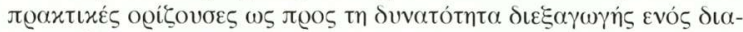

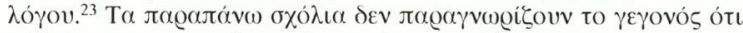

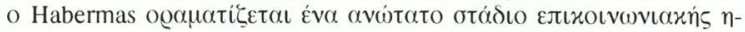

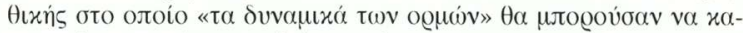

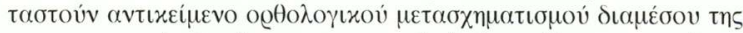

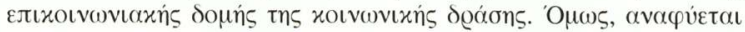

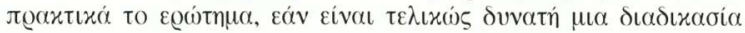

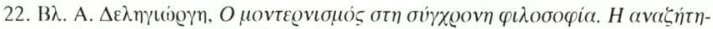

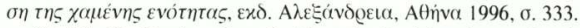

23. B $\lambda$. H. Girndt, «Zum Problem der Legitimation politischen Handelns. Eine

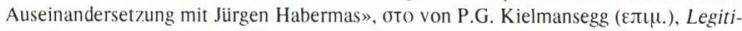
mationsprobleme politischer Systeme, Westdeutscher Verlag, Opladen 1976, б. 63. 


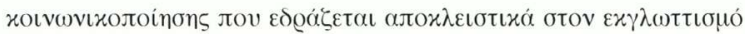

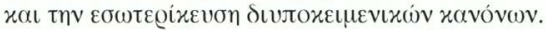

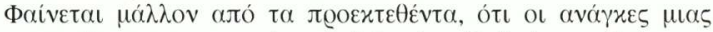

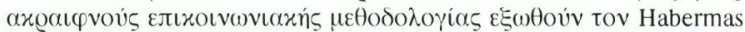

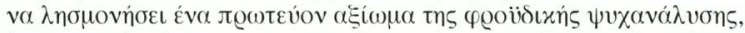

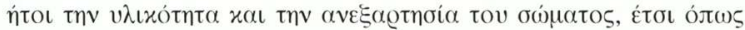

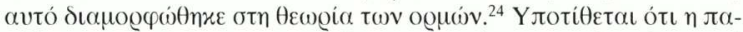

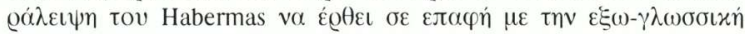

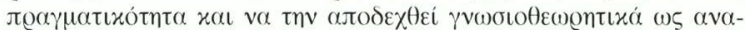

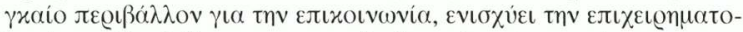

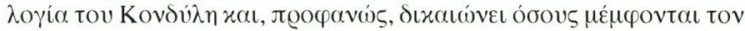

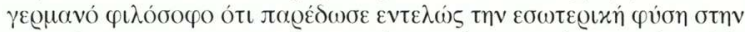

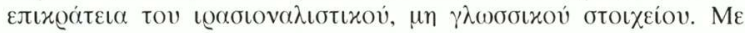

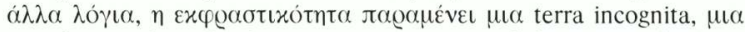

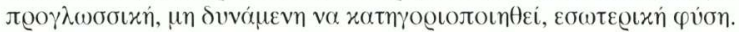

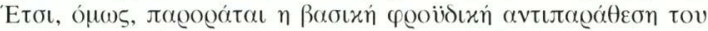

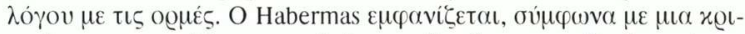

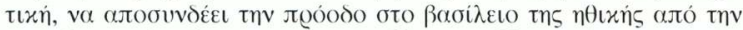

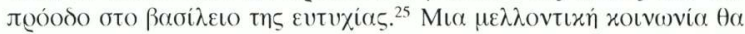

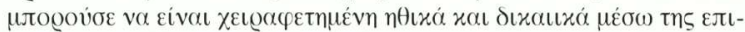

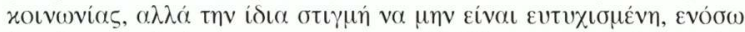

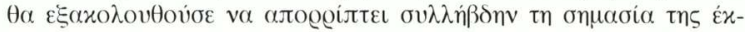

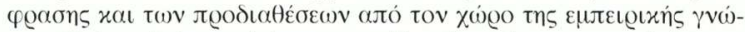

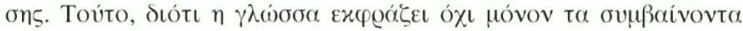

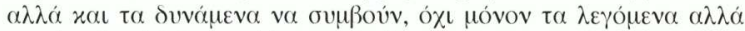

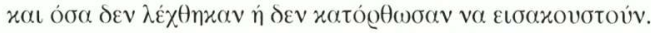

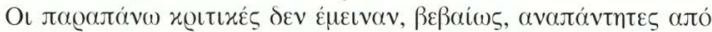

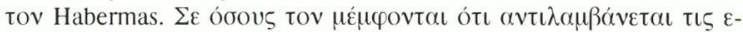

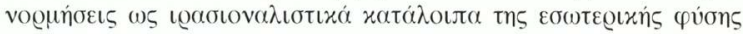

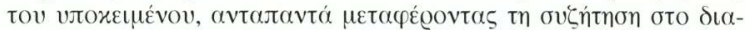

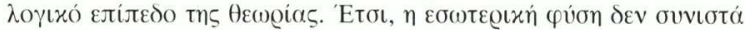

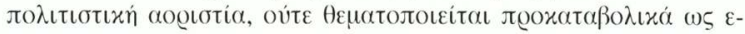

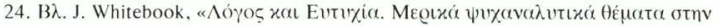

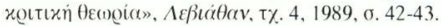

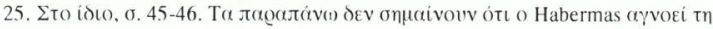

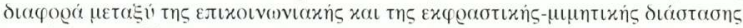

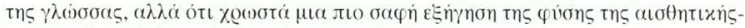

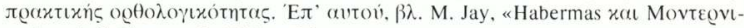

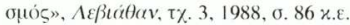




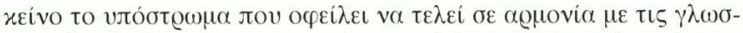

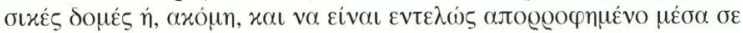

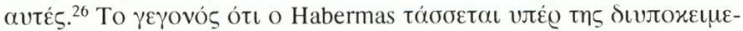

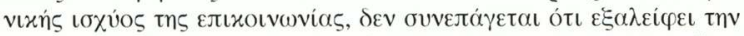

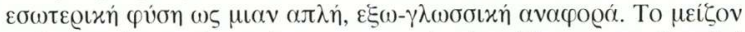

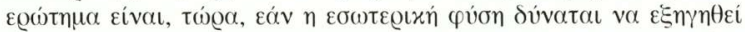

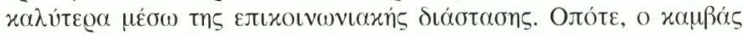

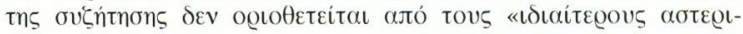

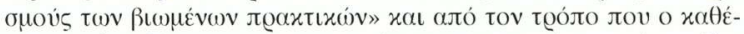

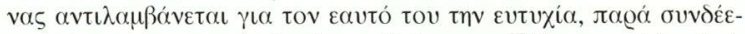

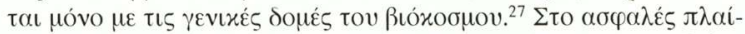

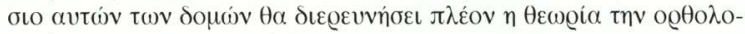

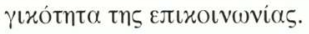

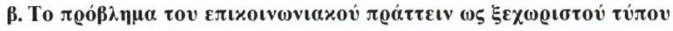

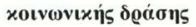

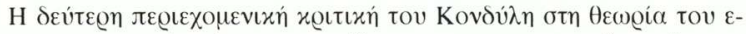

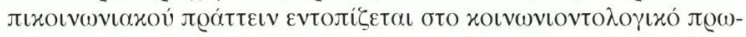

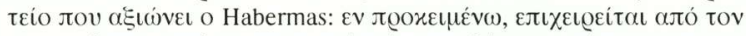

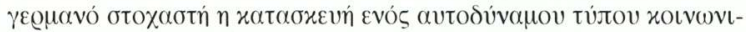

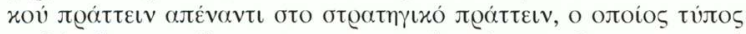

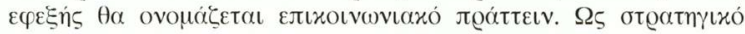

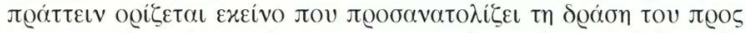

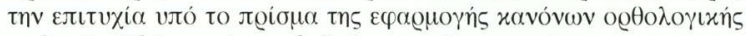

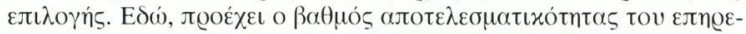

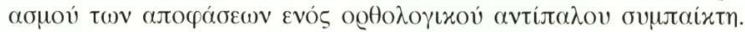

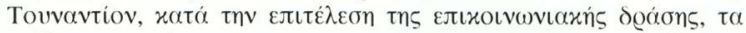

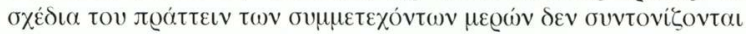

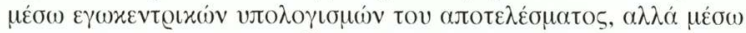

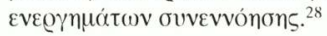

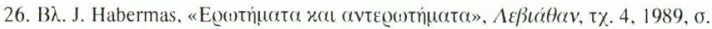
69-70.

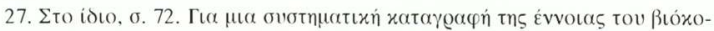

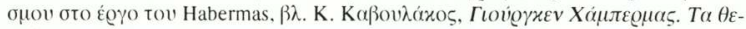

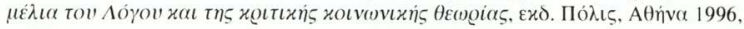

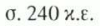

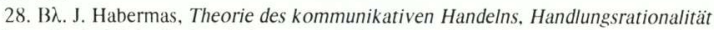

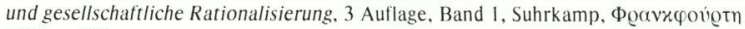
1985, б. 385. 


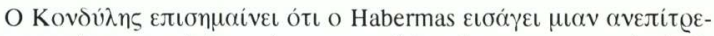

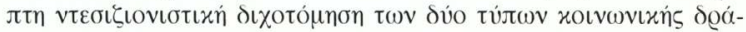

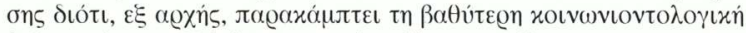

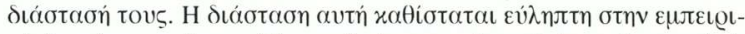

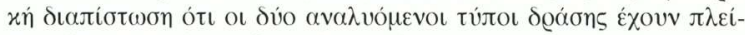

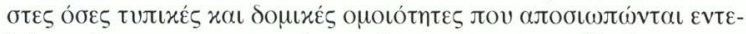

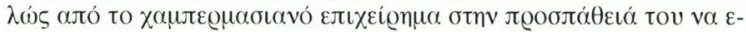

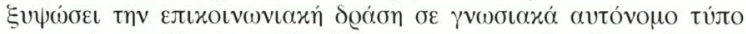

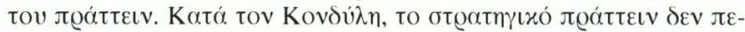

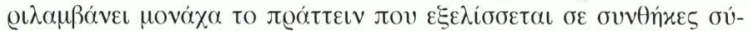

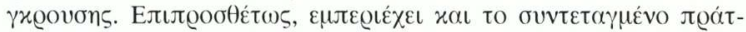

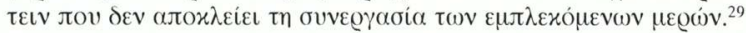

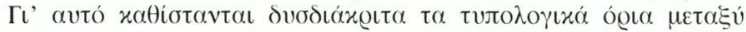

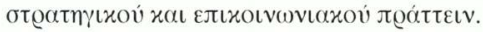

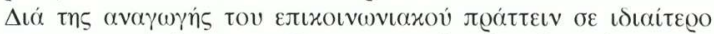

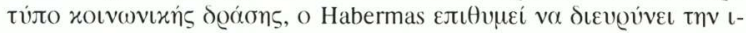

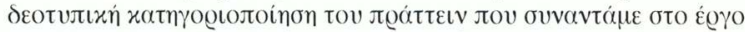

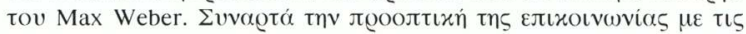

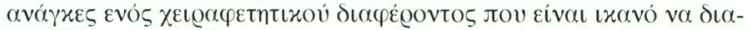

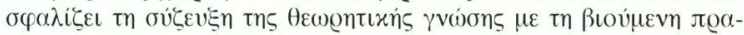

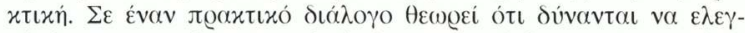

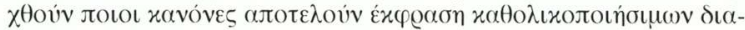

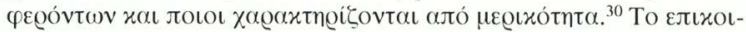

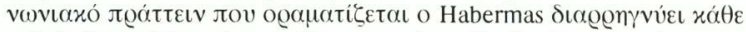

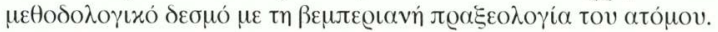

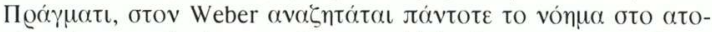

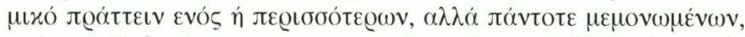

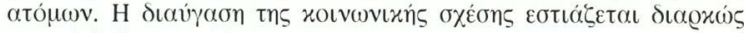

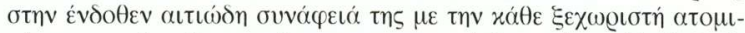

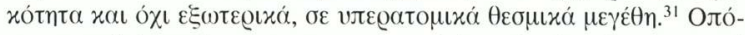

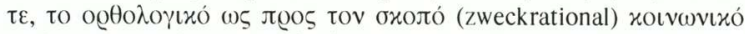

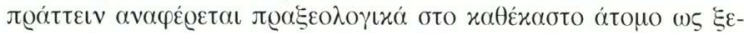

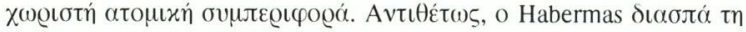

29. P. Kondylis, ó. $\pi$., б. 411 .

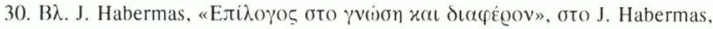

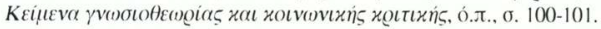

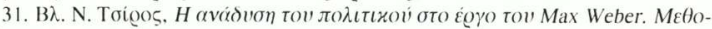

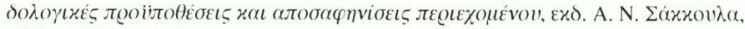
Atruva 2001, б. 61-62. 


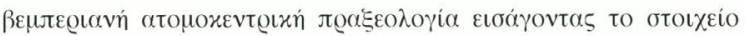

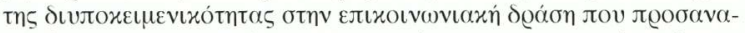

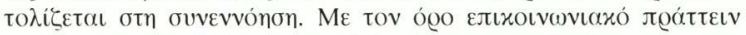

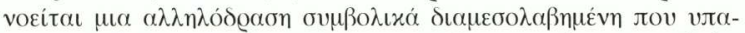

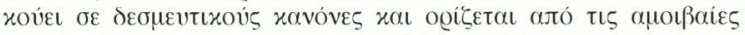

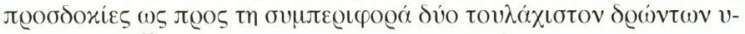

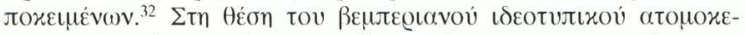

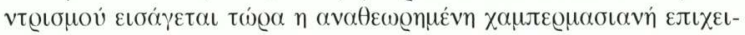

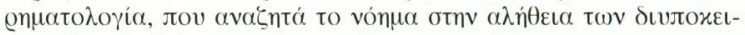

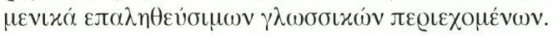

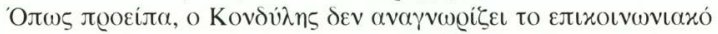

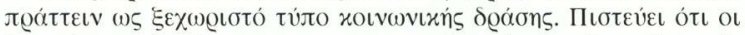

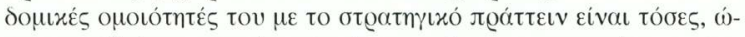

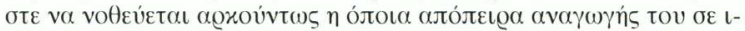

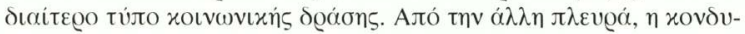

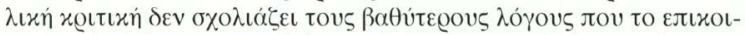

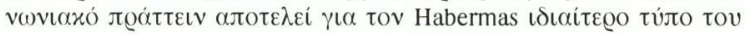

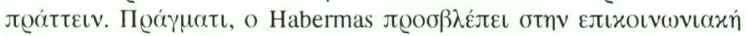

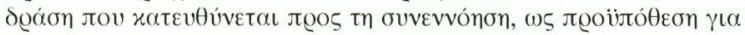

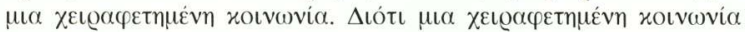

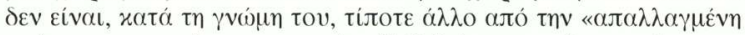

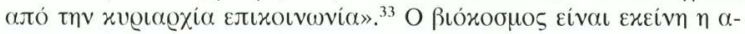

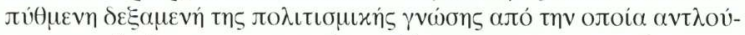

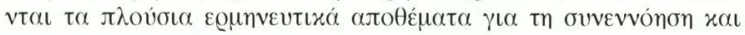

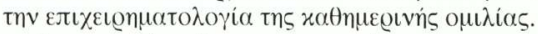

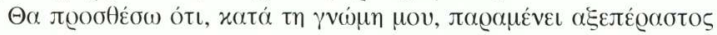

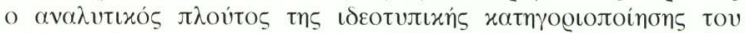

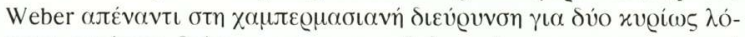

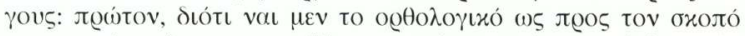

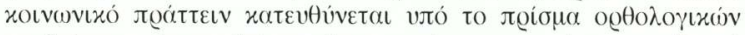

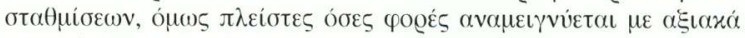

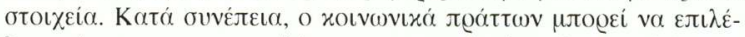

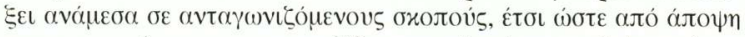

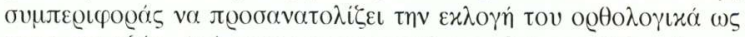

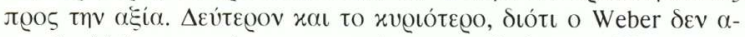

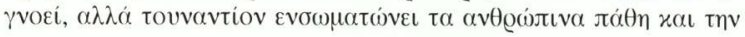

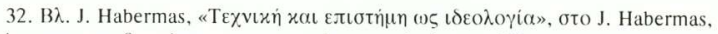

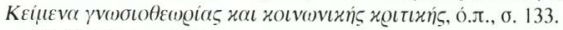

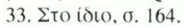




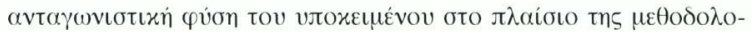

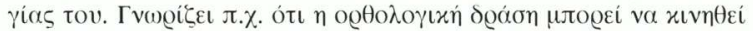

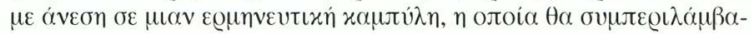

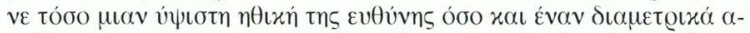

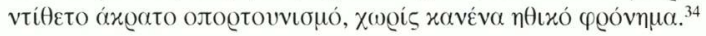

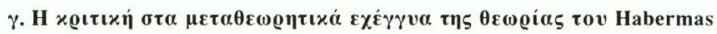

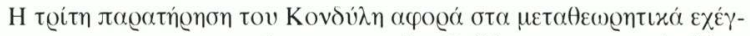

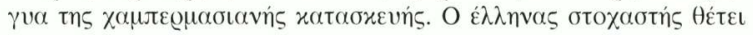

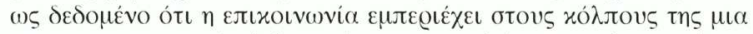

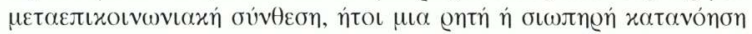

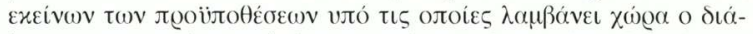

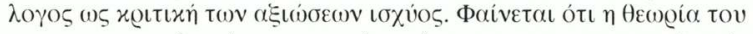

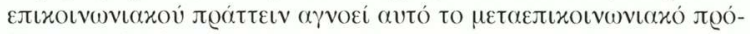

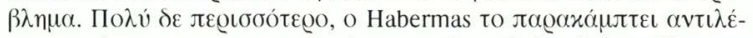

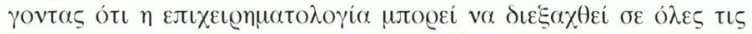

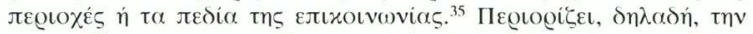

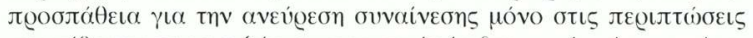

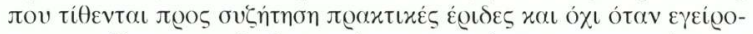

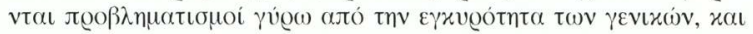

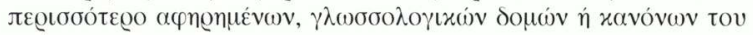

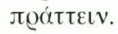

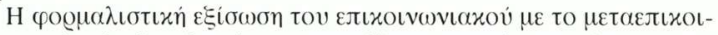

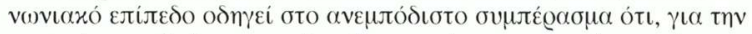

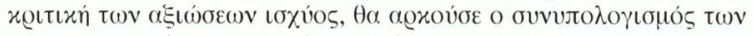

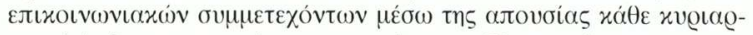

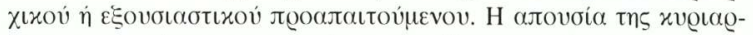

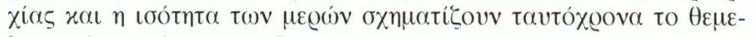

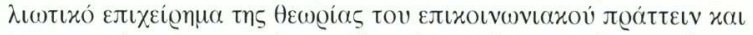

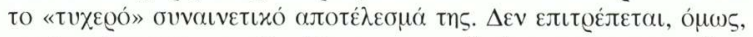

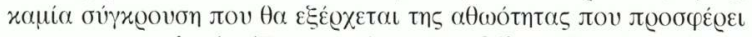

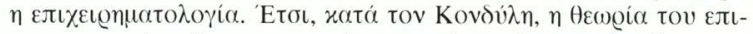

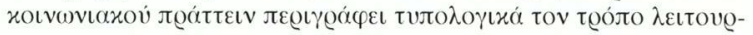

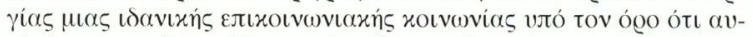

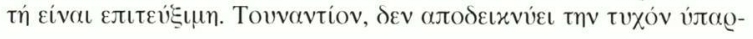

34. B $\lambda$. J. Winckelmann, Legitimität und Legalität in Max Webers Herrschaftssoziologie, Mohr Verlag, Tübingen 1952, б. 28.

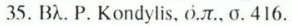




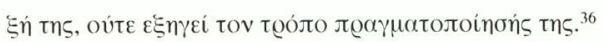

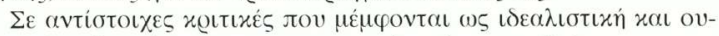

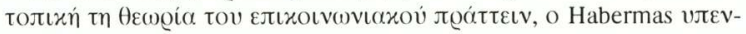

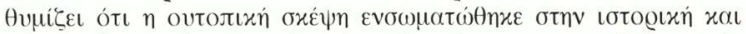

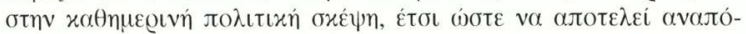

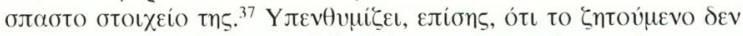

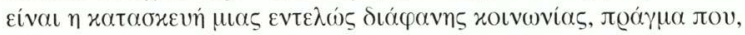

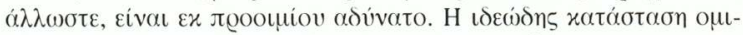

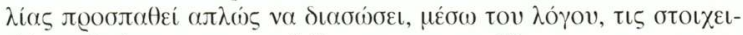

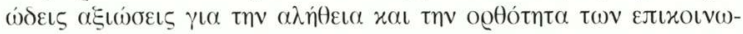

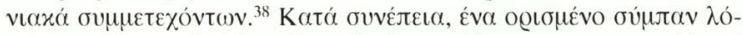

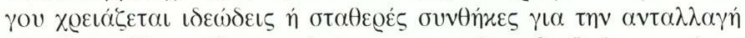

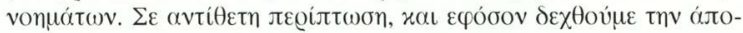

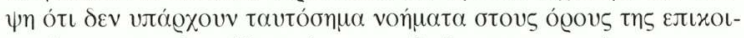

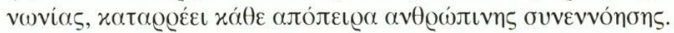

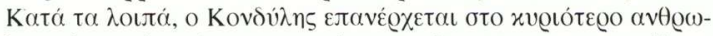

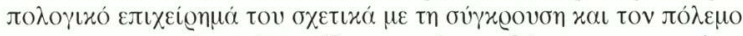

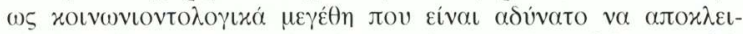

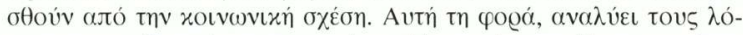

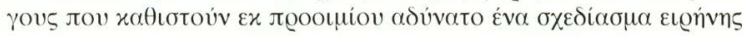

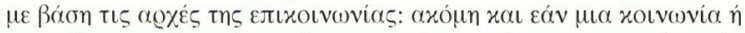

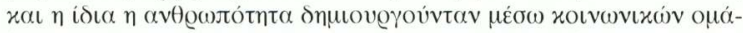

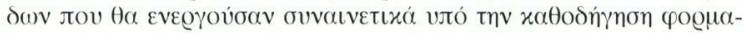

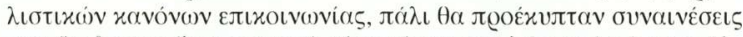

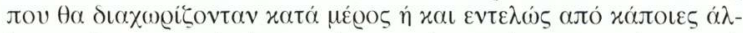

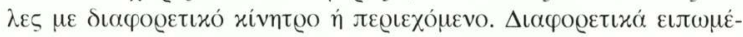

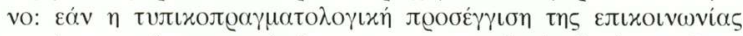

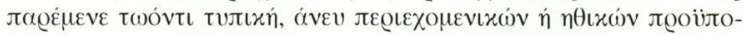

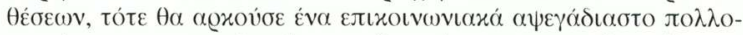

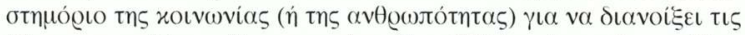

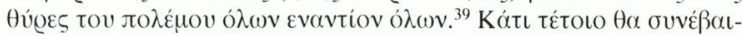

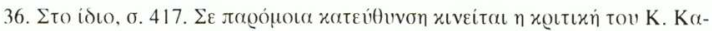

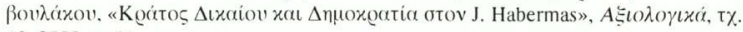
13, 2000, б. 81 .

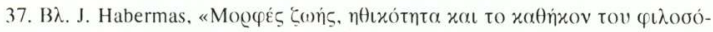

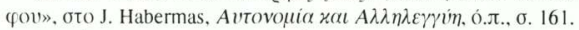

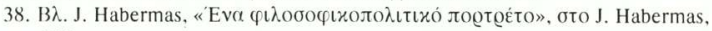
O..T., б. 130.

39. P. Kondylis, o.j., б. 418. 


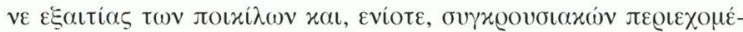

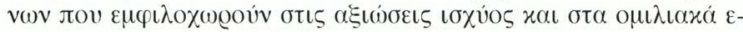

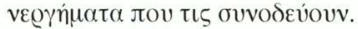

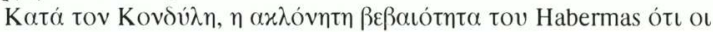

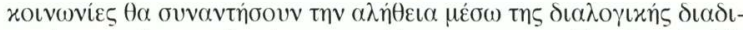

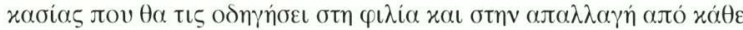

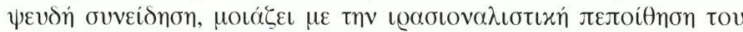

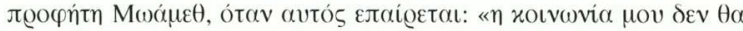

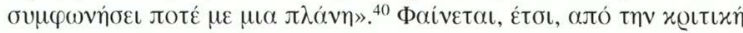

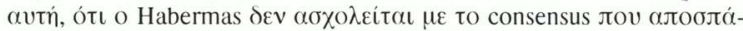

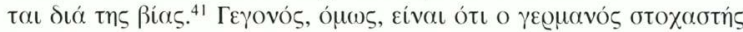

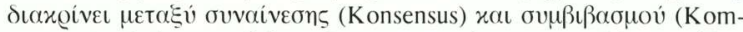

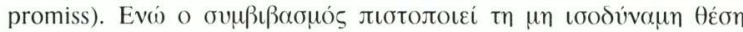

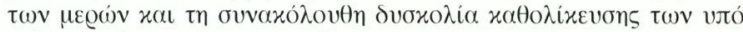

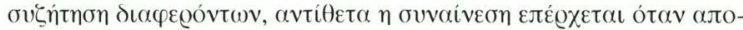

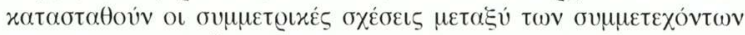

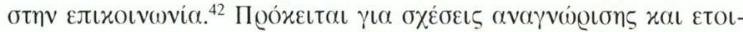

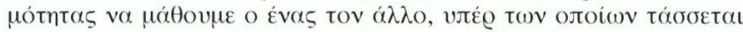

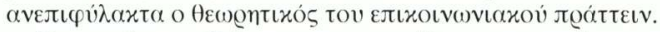

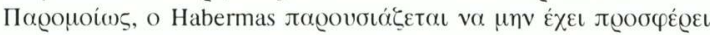

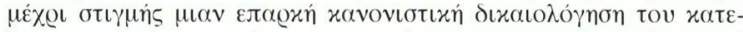

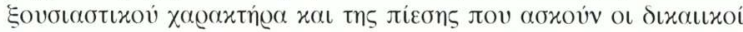

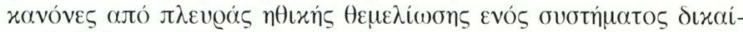

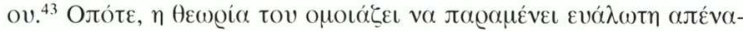

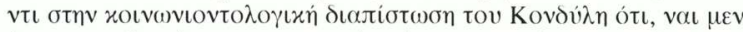

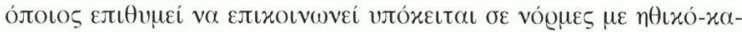

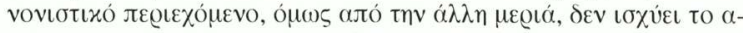

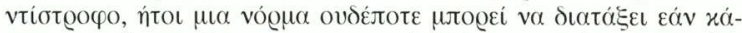

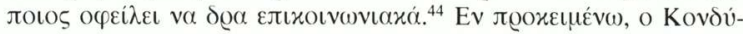

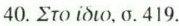

41. 'E $\pi$ ' avtov', $\beta \lambda$. R. Münch, Legitimität und politische Macht, Westdeutscher Verlag, Opladen 1976, б. 43.

42. B $\lambda$. J. Habermas, Legitimationsprobleme im Spaetkapitalismus, Suhrkamp Verlag, Фoavxqoígtn 1973, б. 153-155.

43. 'Etol. K.O. Apel, «Diskursethik vor der Problematik von Recht und Politik: können die Rationalitätsdifferenzen zwischen Moralität, Recht und Politik selbst noch durch die Diskursethik normativ - rational gerechtigt werden?», oto von K.O. Apel -

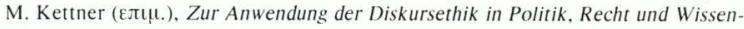
schaft, 2 Aufl., Suhrkamp Verlag, Фoavx.povetn 1993, б. 44.

44. P. Kondylis, o.л., б. 419. 


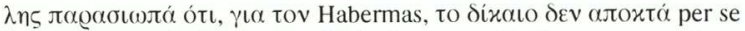

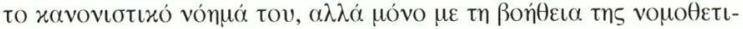

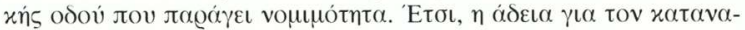

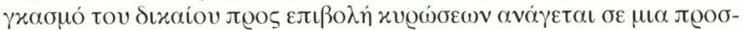

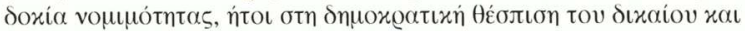

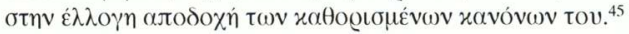

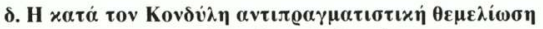

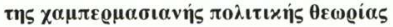

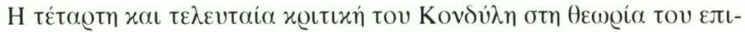

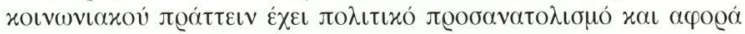

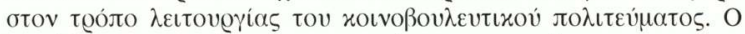

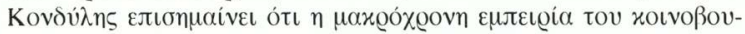

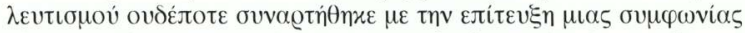

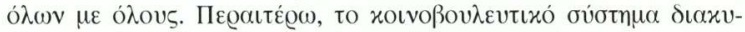

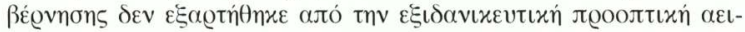

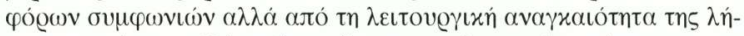

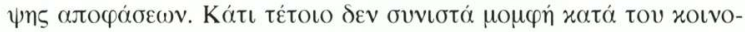

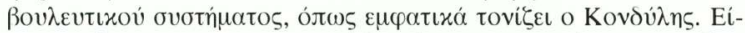

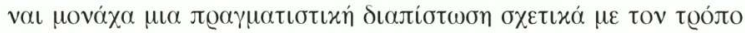

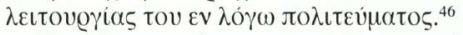

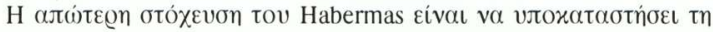

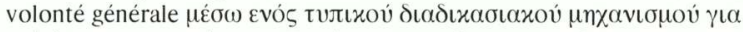

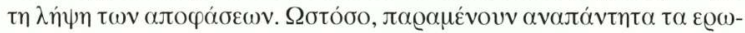

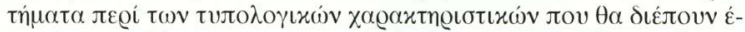

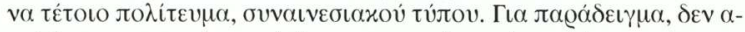

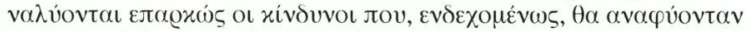

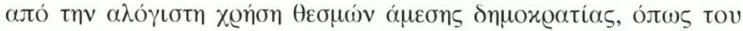

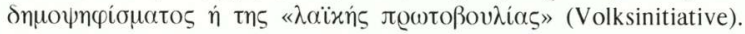

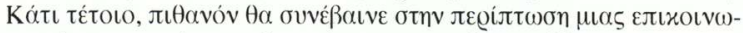

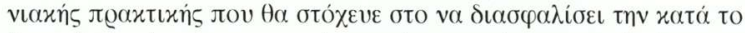

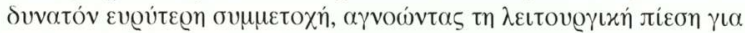

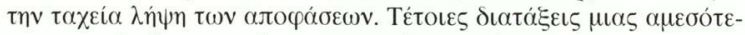

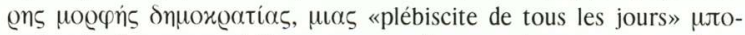

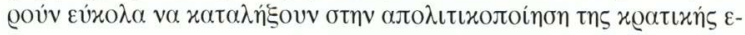

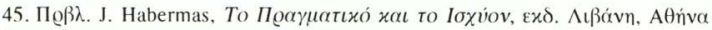
$1996, \sigma .74$.

46. P. Kondylis, O.л., б. 420. 


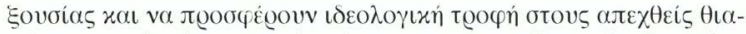

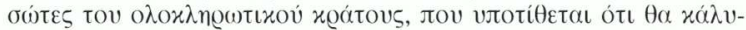

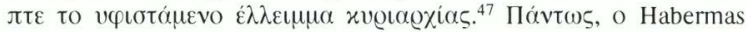

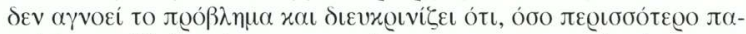

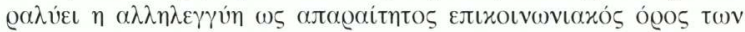

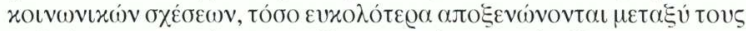

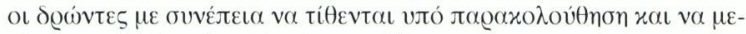

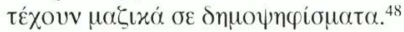

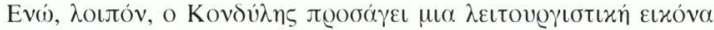

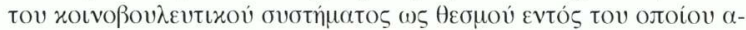

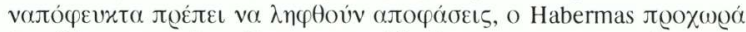

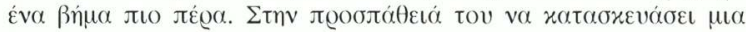

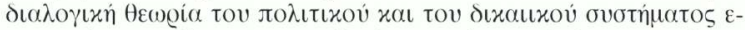

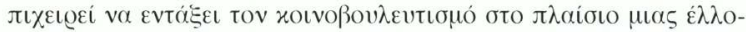

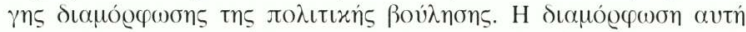

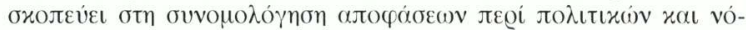

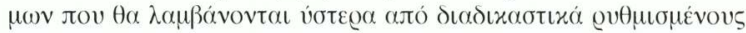

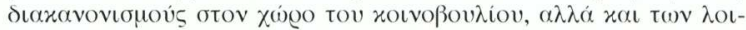

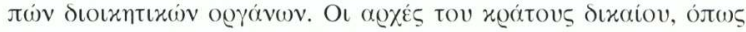

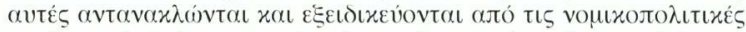

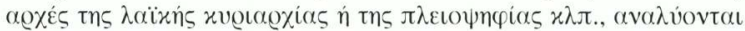

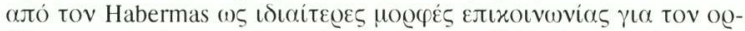

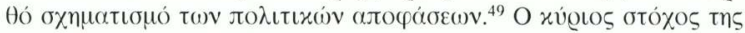

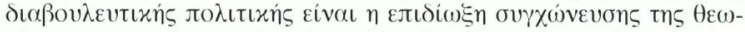

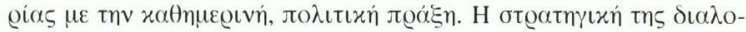

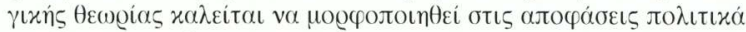

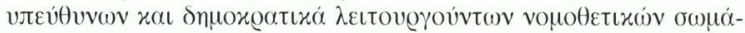

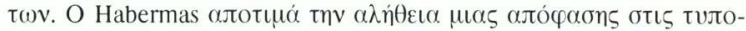

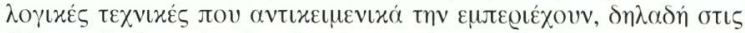

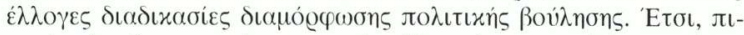

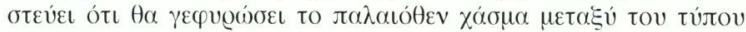

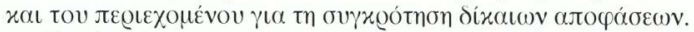

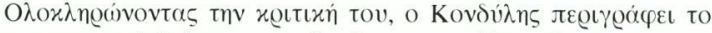

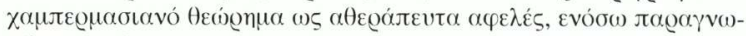

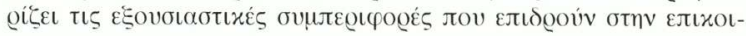

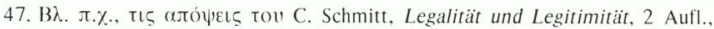
Duncker und Humblot Verlag. Beoohivo 1968, б. 92-93.

48. B $\lambda$. J. Habermas, o.j., б. 487-488.

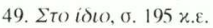




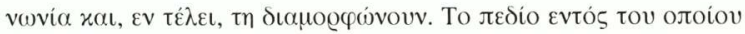

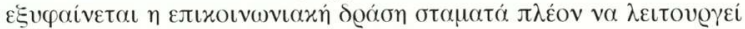

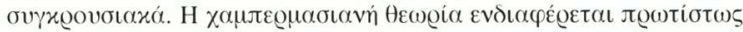

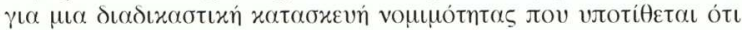

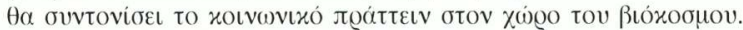

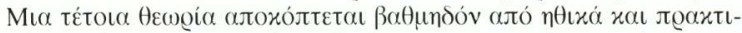

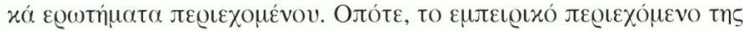

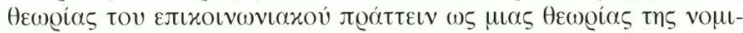

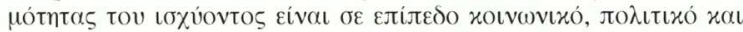

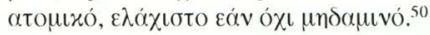

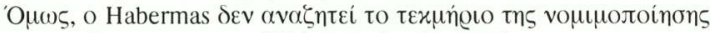

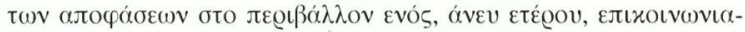

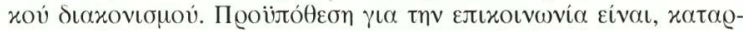

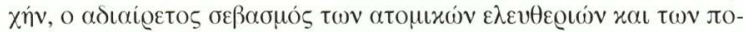

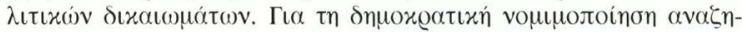

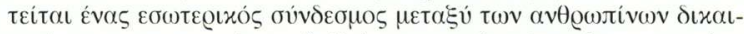

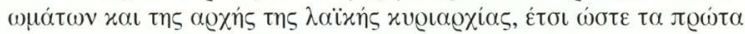

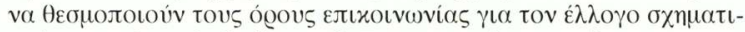

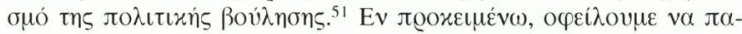

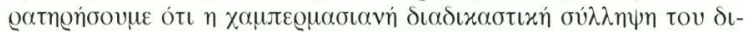

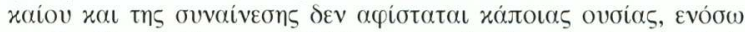

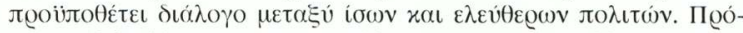

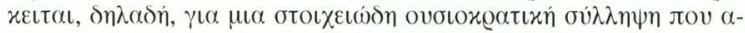

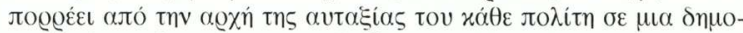

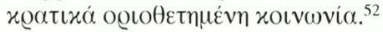

50. 'Eл' autoú M.V. Bader, «Theorie des kommunikativen Handelns als Theorie der Legitimität», Das Argument. Zeitschrift für Philosophie und Sozialwissenschaften, $27 \mathrm{Jg}$, Heft 151, 1985, б. 367-368.

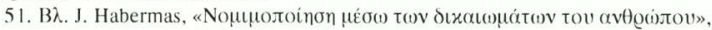

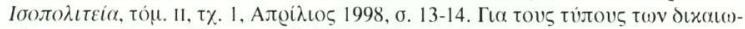

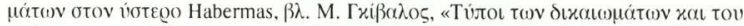

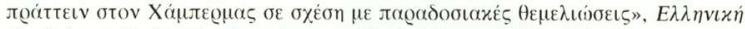

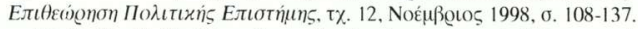

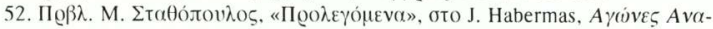

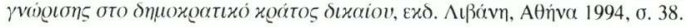




\section{TEAIKA $\Sigma Y M \Pi E P A \Sigma M A T A$}

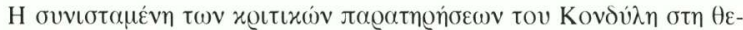

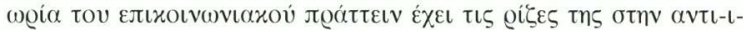

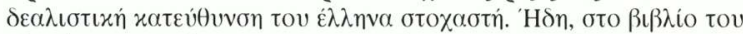

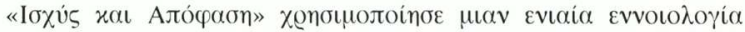

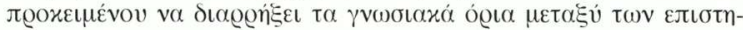

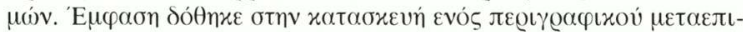

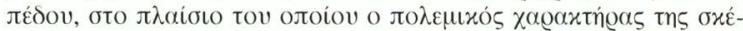

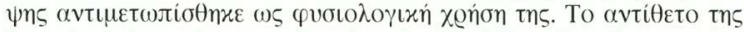

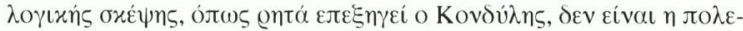

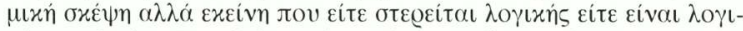

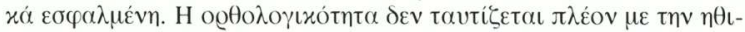

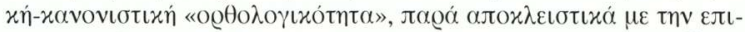

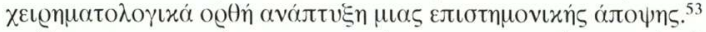

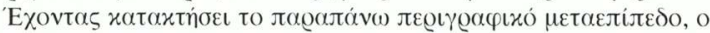

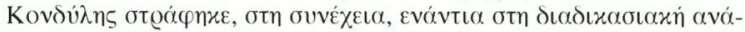

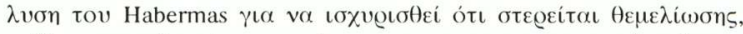

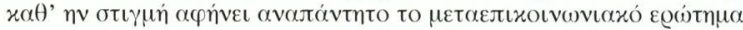

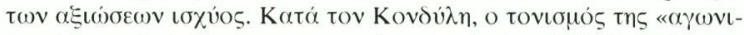

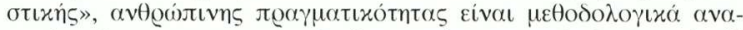

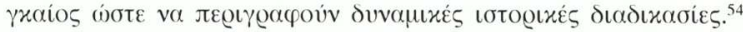

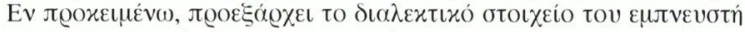

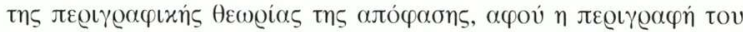

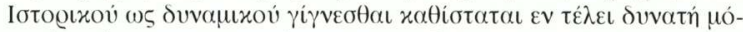

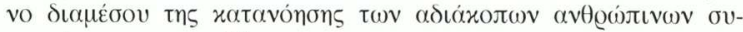

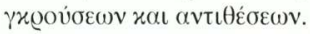

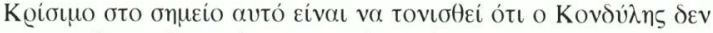

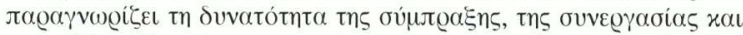

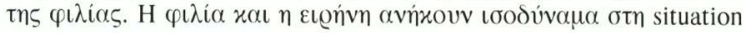

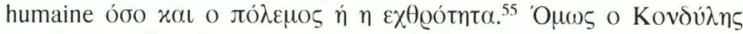

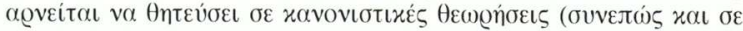

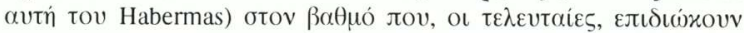

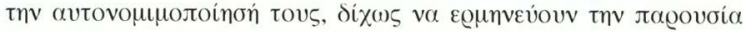

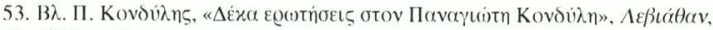
$\tau \chi .15,1994, \sigma .15$.

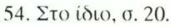

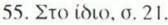




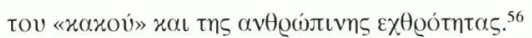

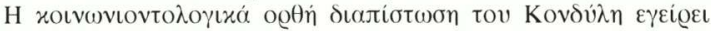

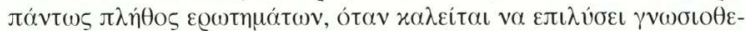

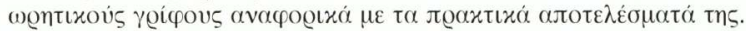

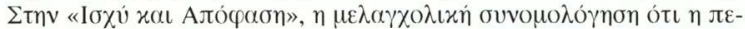

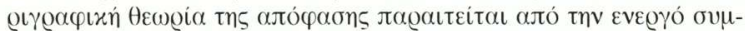

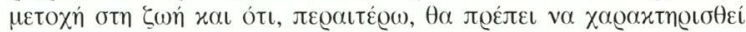

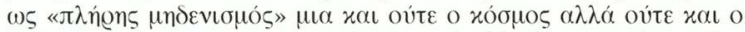

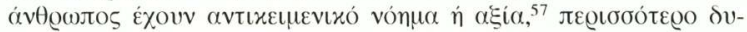

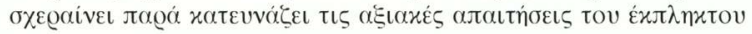
$\alpha v \alpha \gamma v \omega \dot{\omega} \sigma \tau$.

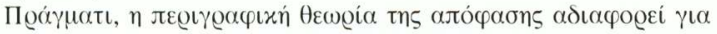

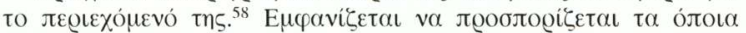

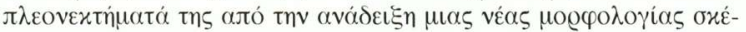

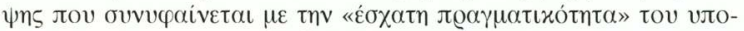

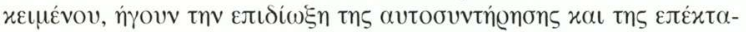

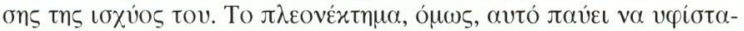

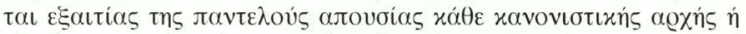

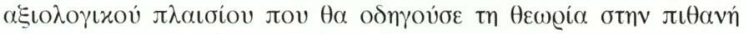

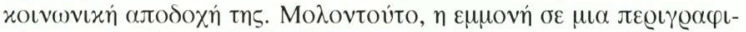

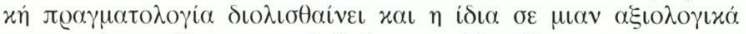

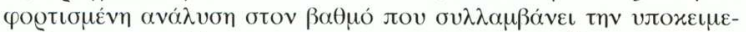

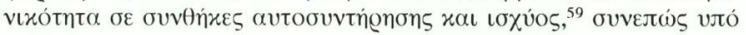

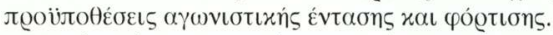

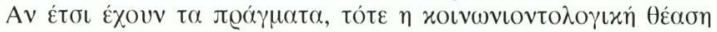

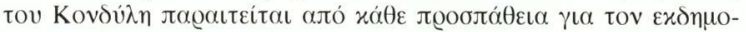

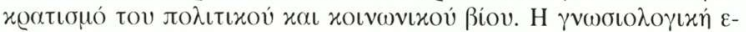

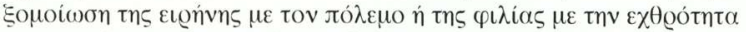

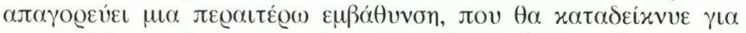

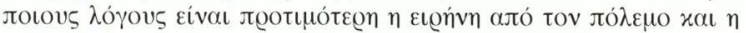

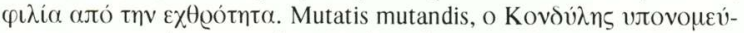

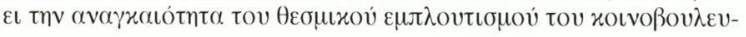

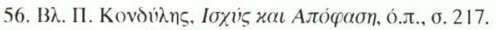

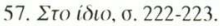

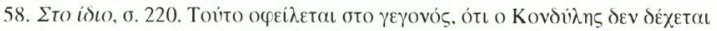

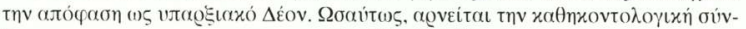

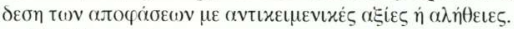

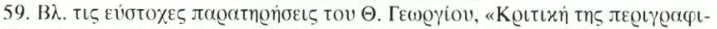

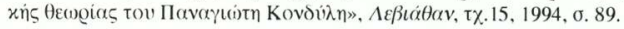




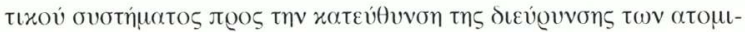

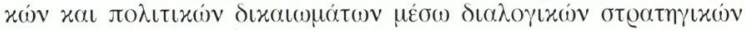

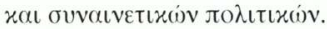

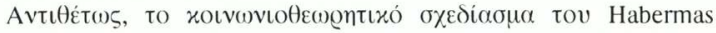

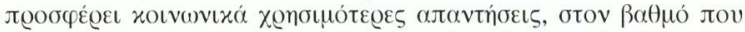

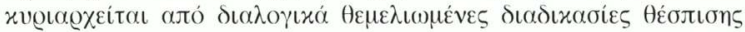

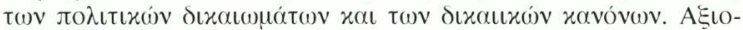

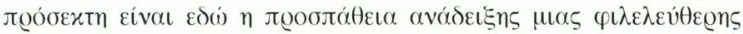
on

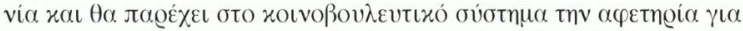

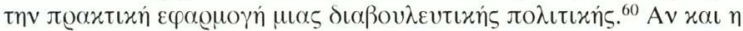

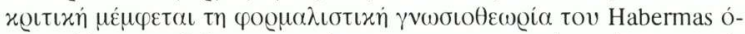

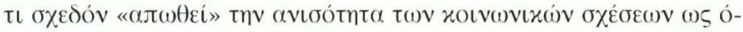

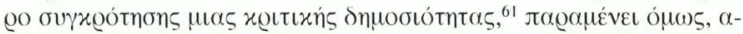

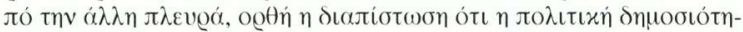

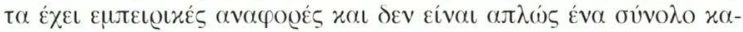

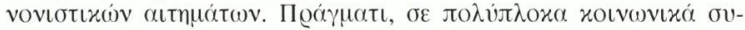

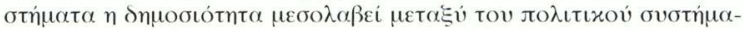

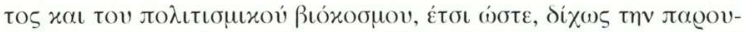

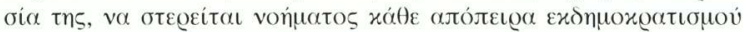

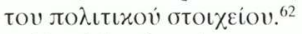

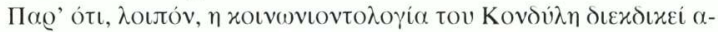

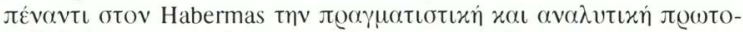

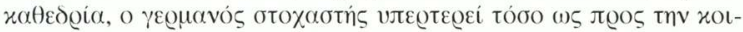

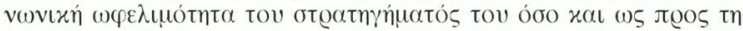

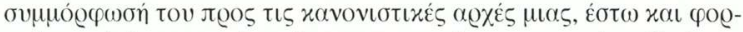

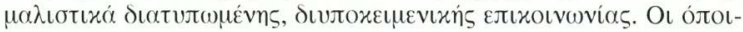

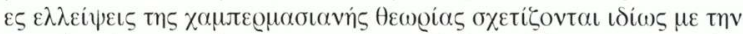

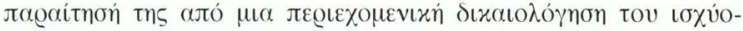

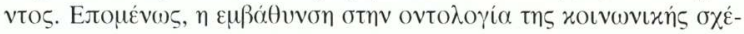

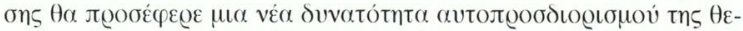

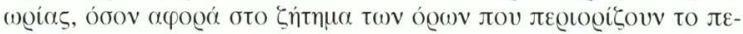

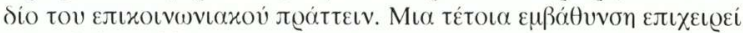

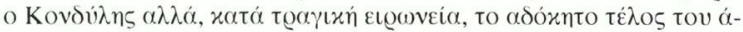

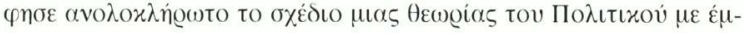

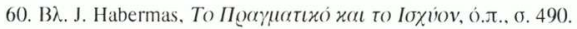

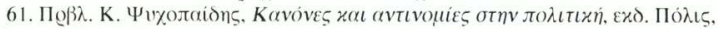
Atrives 1999, o. 549.

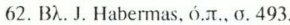




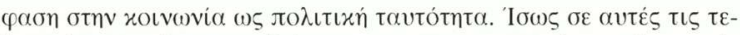

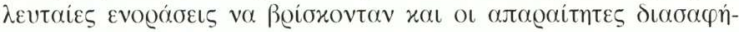

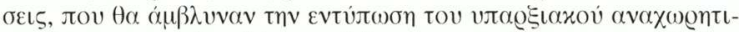

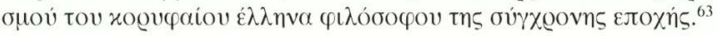

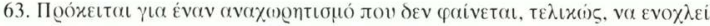

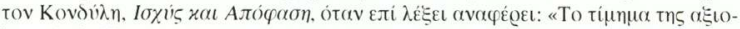

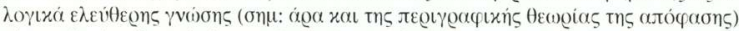

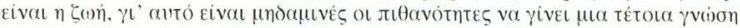

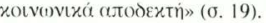

